\title{
Factors affecting in vitro embryo production: insights into dromedary camel
}

\author{
Adel R. Moawad ${ }^{1, *}$, Ibrahim M. Ghoneim ${ }^{1,2}$, Gamal M. Darwish ${ }^{3}$, Magdy R. Badr ${ }^{3}$, \\ Diya A. El-Badry ${ }^{3}$ and Abou Bakr A. EL-Wishy,* \\ ${ }^{1}$ Department of Theriogenology, Faculty of Veterinary Medicine, Cairo University, Giza 12211, Egypt \\ ${ }^{2}$ Department of Clinical Sciences, College of Veterinary Medicine, King Faisal University, Al Ahsa 31982, Kingdom of \\ Saudi Arabia \\ ${ }^{3}$ Department of AI and ET, Animal Reproduction Research Institute, Agriculture Research Centre, Giza 12556, Egypt
}

Received April 18, 2020

Revised May 28, 2020

Accepted June 2, 2020

\section{*Correspondence}

Adel R. Moawad

E-mail: adelreda902@hotmail.com

ORCID

https://orcid.org/0000-0003-4397-9688

Abou Bakr A. EL-Wishy

E-mail: bakerelwishy_2006@yahoo.com

ORCID

https://orcid.org/0000-0002-0385-1287

\begin{abstract}
The Dromedary camel (Camelus dromedaries) is an important species because of its ability to produce good quality meat, milk, and fibers under harsh environmental conditions. Camels are also crucial for transportation, racing, and as draft animals in agriculture. Therefore, dromedary camels play a critical role in the economy for millions of people living in the arid part of the world. The inherent capability of camels to produce meat and milk is highly correlated with their reproductive performance. Compared with other domestic species, the reproductive efficiency in camelids is low. Although recent reproductive technologies such as in vitro fertilization (IVF) and somatic cell nuclear transfer (SCNT) have been successfully applied to camelids and the birth of live offspring following these technologies has been reported; in vitro embryo production (IVP) has lagged in this species. The development of the IVP system for dromedary camels may be a useful tool for the genetic improvement of this species. IVP in farm animals includes three main steps; in vitro maturation (IVM) of an oocyte, IVF of a matured oocyte, and in vitro culture (IVC) of fertilized oocyte up to the blastocyst stage. This review aims to summarize various factors that influence oocyte quality, IVM, and in vitro embryo development in dromedary camel.
\end{abstract}

Keywords: dromedary camel, embryo, IVM/IVF/IVC, oocytes, quality

\section{INTRODUCTION}

The camel (Camelus dromedarius, one-humped camel, Arabian camel, or dromedary) is an essential livestock species uniquely adapted to hot and arid environments. Camel is a multipurpose animal with high productivity of meat and milk even when it is fed on a diet with high fibers and low nutritional value. The dairy type of dromedary has a unique potential for milk production and may have higher production capability than other domestic animals. Milk production of dromedaries varies from $1000 \mathrm{~kg}$ to $9000 \mathrm{~kg}$ per lactation period (Köhler-Rollefson, 1993). Camels also produce fibers of good qualities; for example, camels' hides were found to be $20 \%$ superior in durability and tanning qualities than cattle hides. Meat yield at slaughter varies from $32 \%$ to $40 \%$ depending on the sex and age of the animals (Tibary and Anouassi, 1997). Camels are also used for transportation, racing, 
and as draft animals in agriculture. Therefore, dromedary camels play a significant role in the economy for millions of people living in the arid part of the world. Full exploitation of production of camel milk and meat is only possible when the reproductive performance is improved. However, the reproductive efficiency in camelids is low partly due to the late onset of puberty, early embryonic mortality, seasonality, and the length of the gestation period (13 months). Although recent reproductive technologies such as in vitro fertilization (IVF) (Khatir et al., 2004, 2005, 2009; Moawad, 2005; Khatir and Anouassi, 2006; Wani, 2009; Wani et al., 2010; Moawad et al., 2012a; Fathi et al., 2014; Fathi and El-Shahat, 2017; Fathi et al., 2018) and somatic cell nuclear transfer (SCNT) (Wani et al., 2010) have been successfully applied to camelids and birth of live offspring following these technologies has been reported (Khatir and Anouassi, 2006; Wani et al., 2010), in vitro embryo production (IVP) is still not welldeveloped in this species compared with other domestic species. In many species such as cattle, in vitro oocyte maturation (IVM), and subsequent embryo production is commonly applied and gaining popularity. In 2011, approximately $38 \%$ of the world's bovine embryos were produced by in vitro technology (Stroud, 2012). The development of an IVP system for dromedary camels may be a useful tool for the genetic improvement of this species. IVP in farm animals includes three main steps; IVM of an oocyte, IVF of a matured oocyte, and in vitro culture (IVC) of fertilized oocyte up to the blastocyst stage. Each step in this procedure is critical to obtain viable embryos that can establish pregnancy and produce healthy offspring after transfer to surrogate mother. Successful IVF has three main components, oocytes capable to be fertilized, spermatozoa capable to penetrate and fertilize the oocyte and in vitro conditions which facilitates the full expression of these capabilities (Brackett and Zuelkea, 1993). This review aims to summarize various factors that influence oocyte quality, IVM, and in vitro embryo development in dromedary camel.

\section{HISTORY OF IVP}

IVM was first reported by (Pincus and Enzmann, 1935). They made several observations about the spontaneous nature of meiosis when rabbit ova were removed from antral follicles. They carefully described events such as germinal vesicle breakdown (GVBD) and metaphase-II (MII) formation during in vivo oocyte maturation. They noted that these events could be copied in vitro, without the need for hormone supplementations (Pincus and Enzmann, 1935). In farm animals, one of the earliest attempts for doing IVF of artificially matured oocytes was reported in cattle in 1970 (Sreenan, 1970). A few years later, the birth of the first calf from IVF of ovulated oocytes was reported (Brackett et al., 1982). Since then, many studies have been carried out to develop this technique in farm animals because of its potential applications to animal production. In buffalo, the birth of the first IVF calf was reported in 1991 (Madan et al., 1991). In small ruminants, the first kid born from IVF of ovulated oocytes was published in 1985 (Hanada, 1985) and the first lamb in 1986 by Cheng and colleagues (Cheng et al., 1986). In equine, the birth of the first foal produced by IVF was documented in France in 1991 by Palmer et al. (Palmer et al., 1991). In porcine, the birth of IVF piglets was reported in 1993 by Yoshida et al. (Yoshida et al., 1993). In camelids, the first successful IVM of oocytes and IVF were achieved in the llama in 1992 and 1994, respectively (Del Campo et al., 1992; Del Campo et al., 1994a; Del Campo et al., 1994b). To date the birth of a llama or alpaca from the transfer of IVF embryos has not been documented (Trasorras et al., 2017). Bou and colleagues have reported a preliminary study on IVF of bacterin camel oocytes in 1993 (Bou et al., 1993). In 2006, the birth of live offspring from IVM/IVF and IVC of dromedary camel oocytes had been reported by Khatir and Anouassi (Khatir and Anouassi, 2006). Despite the studies that have been done on IVP in the past 30 years in different species, the results obtained are still inconsistent. For example, in cattle, despite the high rates of oocyte IVM (approximately 90\%) and IVF (about 80\%), blastocyst development rates are only $30 \%$ to $40 \%$ reviewed by (Lonergan and Fair, 2014). In pigs, IVP still presents problems such as polyspermic fertilization and low blastocyst formation rates reviewed by (Grupen, 2014). In goats and sheep, there are relatively few studies on IVP, but the percentage of blastocysts produced from IVM/IVF/IVC ranges from $20 \%$ to $30 \%$ reviewed by (Paramio and Izquierdo, 2016). In camelids, limited success has been achieved utilizing in vitro technologies, and the percentages of blastocysts ranged from $0 \%$ to $35 \%$ in both llama and dromedary camels (Del Campo et al., 1994b; Khatir et al., 2004, 2005; Moawad, 
2005; Khatir and Anouassi, 2006; Wani, 2009; Moawad et al., 2012a; Fathi et al., 2014; Fathi and El-Shahat, 2017; Fathi et al., 2018).

\section{OOCYTE MATURATION}

Oocyte maturation, whether in vivo or in vitro, is one of the most critical steps of embryo development. Oocyte, in most mammals, entered the initial phases of meiosis and stopped at prophase I during embryogenesis. Before restoring meiosis-I, the oocyte is $2 \mathrm{n}$ (Lonergan and Fair, 2016). After that, it arrests at the metaphase-II stage, which characterized by the production of the first polar body, and oocyte now has DNA pair of $1 \mathrm{n}$. After fertilization, there is a production of the second polar body, and an embryo becomes diploid (2n). In vivo, resumption of meiosis is initiated by a preovulatory luteinizing hormone (LH) surge. During the period between the LH surge and ovulation, the oocytes undergo nuclear and cytoplasmic maturation.

Nuclear maturation is a sequence of nuclear modifications that occur during recovery and progression of meiosis, resulting in haploid chromosome complements (Marteil et al., 2009). It lasts for $24 \mathrm{~h}$ in cattle and sheep, $44 \mathrm{~h}$ in pigs, and $36 \mathrm{~h}$ in horses and dromedary camels. Cytoplasmic maturation involves the ability of oocytes to block polyspermy, decondense penetrated spermatozoa, and form pronuclei after fertilization. Also, it requires the redistribution of organelles and the accumulation of granules along the oolemma (van den Hurk and Zhao, 2005). The changes associated with these steps for in vivo maturation can be replicated in vitro by collecting the oocytes from ovarian follicles of living or slaughtered animals and subjected them to an environment to complete the maturation process in a laboratory dish. Appropriate selection of oocyte in the laboratory is critical for successful embryo production. The presence of intact cumulus cell layers surrounding the oocyte and a homogenous looking cytoplasm have been the best indicators of the quality of immature oocytes and their ability to undergo maturation and embryonic development. Despite numerous advances in IVM procedures in different species, oocyte maturation rates are still low in many species include camelids. Various factors include, oocyte quality, follicular size, type of culture media, media supplements, methods of oocyte retrieval, temperature, and maturation time have been identified to play a crucial role in oocyte development in vitro in cattle. However, no comprehensive review addresses the influence of these factors on oocyte quality and IVM in dromedary camel has been published. Therefore, identifying the factors that affect dromedary camel oocyte maturation and in vitro development is important to improve the IVP in this species.

\section{FACTORS AFFECTING OOCYTE QUALITY AND IVM IN DROMEDARY CAMEL}

\section{Sources of oocytes}

The mammalian oocyte is the cornerstone for a wide range of recent reproductive technologies such as IVP, preservation of genetic diversity, generation of highvalue products through transgenesis, and cell therapies through the stem cell approach. The increasing demand for mature oocytes can be covered by an abundant source of oocytes (Motlík et al., 2000). Oocytes can be collected either in vivo from live animals or in vitro after ovarian ablation from slaughtered animal or after ovariectomy.

\section{1) In vivo methods for oocyte recovery}

Two ways are commonly used for the collection of oocytes from live animals, namely, surgically or by transvaginal ultrasound-guided aspiration (ovum pick up; OPU). Both methods have been used for retrieval of oocytes in camelids (Tibary and Anouassi, 1997; Brogliatti et al., 2000; Tinson et al., 2001; Sansinena et al., 2003; Ratto et al., 2007; Sansinena et al., 2007; Trasorras et al., 2009; Berland et al., 2011; Tibary et al., 2015). However, surgical collection of oocytes has some drawbacks; for example, the oocytes are usually in an advanced stage of maturation, primarily if the technique was performed $12 \mathrm{~h}$ to $24 \mathrm{~h}$ after induction of ovulation with human chorionic gonadotropin (hCG). Furthermore, the follicles become fragile and easy to bleed, resulting in low oocyte recovery rates (Tibary and Anouassi, 1997). In addition to these drawbacks, the surgical method takes time to complete, for example, in dromedary camel, surgical aspiration takes around $30 \mathrm{~min}$ for a single ovary compared to 8-10 min for both ovaries in case of OPU (Tinson et al., 2001). Furthermore, Tinson et al. (2001) showed that using a surgical technique for the collection of camel oocytes resulted in a higher recovery rate (59.6\%) than non-surgical one (29\%). In another study done by Wani and Skidmore 
in 2010, it has been shown that collection of dromedary camel oocytes by OPU resulted in aspiration of an average of $12.12 \pm 7.9$ cumulus-oocyte complexes (COCs) per animal with $77 \%$ recovered oocytes per aspirated follicles (Wani and Skidmore, 2010). More than 90\% of collected COCs were surrounded by loose and expanded cumulus cells (Wani and Skidmore, 2010). In the same study, the authors evaluated the maturation rates of collected oocytes. They found that the proportions of matured oocytes obtained at 28-29 h (91.2 \pm 4.1$)$, and 26-27 h (82.1 \pm $3.4)$ were significantly higher when compared with those obtained at 24-25 h (40.4 \pm 16.3$)$ after gonadotropinreleasing hormone $(\mathrm{GnRH})$ administration (Wani and Skidmore, 2010). In llamas, surgical retrieval of oocytes through flank laparotomy resulted in an 80\% recovery rate which was the highest of any technique (Sansinena et al., 2007). However, it has been reported that collection of oocytes through laparoscopic OPU is safer with relatively similar recovery rates (Bou et al., 1993; Tibary et al., 2007). Transvaginal ultrasound-guided aspiration is a relatively noninvasive, repeatable procedure, but it has the lowest recovery rates ranging from $30 \%$ to $75 \%$ and may be physically impossible in animals of smaller stature, limiting the use of this technique in alpacas (Brogliatti et al., 2000; Tibary et al., 2005; Tibary et al., 2007).

\section{2) Oocyte recovery from slaughtered animals}

The traditional source of oocytes for IVP is slaughterhouse ovaries. Four methods have been described for collection of oocytes from domestic animals after slaughter include dissection of ovarian follicles, aspiration of ovarian follicles, slicing of the ovaries and puncture of visible surface follicles (Lonergan et al., 1991; Martino et al., 1994; Pawshe et al., 1994; Jain et al., 1995; Kumar et al., 1997). It has been reported that slicing of llama' $s$ ovaries yielded a higher number of oocytes than follicular aspiration (27 vs. 6.4 oocytes/llama) (Del Campo et al., 1992; Del Campo et al., 1994b). Another study reported that 1324 COCs could be collected by cutting the surface of llamas' ovaries (46 llamas) with a razor blade (Del Campo et al., 1994a; Del Campo et al., 1995). It is well known that follicular aspiration considered the most suitable method for oocyte retrieval in dromedary camels. This is mainly due to ovarian slicing results in excessive release of blood from hemorrhagic follicles into the collection medium (Purohit et al., 1999). Moreover, the ap- parent protrusion of ovarian follicles on the surface of camel ovaries as spherical, discrete, thick-walled structures (El-Wishy and Hemeida, 1984; Arthur et al., 1985) favored the aspiration method. Previous studies showed that the collection of dromedary camel oocytes by follicular aspiration resulted in higher oocyte recovery rates (4.0 oocytes/ovary) than those recovered by follicle dissection or by ovarian slicing (2.3 and 0.7 oocytes/ovary, respectively) (Purohit et al., 1999). However, in another study slicing of dromedary camel ovaries yielded 5.9 COCs per ovary (Ghoneim, 1999) which was similar to what has been reported by Mahmoud et al. in 2003 after aspiration of dromedary camel ovarian follicles (5.3 oocytes/ovary) (Mahmoud et al., 2003). In the latter study, the recovered oocytes were classified according to their quality into COCs (29.27\%), partial oocytes complex (POC, 32.90\%), denuded oocytes (DO, 32.61\%) and degenerated oocytes (5.21\%) (Mahmoud et al., 2003). In 2001, Abdoon reported that slicing of dromedary camel ovaries increased the oocytes yield as compared to follicular aspiration (10.8 vs. 8.7 oocytes/ovary) (Abdoon, 2001). In the same study, the author showed that aspiration of ovarian follicles by a 20-gauge needle improved oocyte yield and quality than those aspirated by 19-gauge or by 18-gauge needles (Abdoon, 2001). Nowshari (2005) compared three methods for harvesting dromedary camel oocytes namely; follicle aspiration with $18-G$ needle attached to a disposable syringe (method I); follicle aspiration with a needle attached to a constant aspirating pressure $(100 \mathrm{~mm} \mathrm{Hg})$ applied to vacuum pump (method II) and follicle dissection (method III) on oocyte recovery rates. They reported higher oocyte recovery rates in the method III $(482 / 513 ; 94 \%)$ than those in the method I $(341 / 1041 ; 31 \%)$ and method II (249/807; 33\%) (Nowshari, 2005). Also, higher proportions of entirely or partially denuded oocytes were noticed in the method I (31\%) and II (15\%) than in method III (1\%) (Nowshari, 2005). Furthermore, the author reported that IVM rates were higher in oocytes collected by methods II and III than those obtained by the method I (50\% and 49\% vs. 39\%) (Nowshari, 2005). Khatir et al. (2004) retrieved a total of 1598 COCs from 457 slaughtered camel ovaries (average of 3.5 oocytes/ovary) using aspiration method. Eighteen percent (290/1598) were judged to be unsuitable for IVM and were discarded due to degenerated/fragmented cytoplasm and absence of cumulus cells (Khatir et al., 2004). In our studies, we were able to collect 2294 oo- 
cytes from 995 dromedary camel ovaries (an average of 2.3 oocytes/ovary). We also found that $92.2 \%$ of those oocytes were arbitrated as suitable for IVM (Moawad, 2005).

\section{Effect of reproductive status of female dromedary camel}

Camels are induced ovulators, like cats and rabbits, and, therefore, regularly only ovulate in response to the stimulus of mating (El-Wishy, 1987). In the mated animal, ovulation is detected by the rapid disappearance of a mature follicle within 28-36 h of mating. The corpus luteum (CL) that develops can be identified by ultrasonography on Days 4-5 post-mating and reaches maximum size on Days 8-9 (El-Wishy, 1987). It subsequently regresses on Days 9-12 if there is no conceptus in the uterus, which means that in comparison with other species, camels have a relatively short luteal lifespan in the absence of pregnancy (Marie and Anouassi, 1986; Skidmore et al., 1995). In other words, the CL can only be seen during pregnancy (ElWishy et al., 1981). Many authors have studied the effects of reproductive status (pregnant vs. non-pregnant) on oocyte quality and IVM in dromedary camel. For example, a lower number of oocytes per ovary was collected from pregnant camels than those obtained from non-pregnant female dromedaries (10.6 vs. 4.4 oocytes/ovary, respectively) (Ghoneim, 1999). Similarly, another study reported a lower recovery rate from the ovaries of pregnant female dromedary (6.8 oocytes/ovary) than those collected from the ovaries of non-pregnant females (10.5 oocytes/ovary) (Abdoon, 2001). In the same study, the author also demonstrated that the number of category I oocytes (oocytes with 2-4 layers of cumulus cells) was significantly lower in the ovaries of pregnant females than those of nonpregnant ones (5.65 vs. 9.13 oocytes/ovary) (Abdoon, 2001). These observations could be explained based on ovaries collected from pregnant females have lower num- bers of follicles per ovary (14.4 follicles/ovary) compared to the ovaries obtained from non-pregnant females (18.9 follicles/ovary) (Abdoon, 2001). Torner and his colleagues in 2003 were able to recover a total number of 1032 COCs from the ovaries of 47 pregnant and 43 non-pregnant slaughtered dromedary females by using slicing method with recovery rates of 10.3 COCs/ovary in pregnant and 12.5 COCs/ovary in non-pregnant donors (Torner et al., 2003). They divided the retrieved oocytes into oocytes with compact (26.9\% and $28 \%$ ), dispersed $(39.3 \%$ and $46 \%)$, corona radiata $(27.9 \%$ and $21.7 \%$ ) cumulus investments and without cumulus cells (6\% and $4.2 \%$ ) for pregnant and non-pregnant donors, respectively (Torner et al., 2003). Similarly, we noticed that the number of oocytes collected from the ovaries of pregnant (ovaries with CL; Fig. 1A) female dromedary camels was significantly lower (1.3 oocytes/ovary) than those obtained from the ovaries non-pregnant females (2.6 oocytes/ovary, ovaries without CL, Fig. 1B) (Moawad, 2005). Furthermore, we also noticed that the reproductive status of female dromedary affects the quality of retrieved oocytes as the percentage of oocytes selected for IVM were significantly lower in the group collected from the ovaries of pregnant animals than those recovered from non-pregnant ones $(75.0 \%$ vs. 84.6\%) (Moawad, 2005). However, the numbers of degenerated oocytes were significantly higher in the ovaries of pregnant animals than those non-pregnant ones $(25.0 \%$ vs. 15.4\%) (Moawad, 2005). The reproductive status of female dromedary camel affects not only the numbers and the quality of the recovered oocytes, but it also influences the ability of those oocytes to resume meiosis in vitro. For example, a previous study showed that oocytes collected from pregnant females exhibit MI stage at 24-32 $\mathrm{h}$ and MII stage at 36-42 $\mathrm{h}$ post-IVM, however; oocytes retrieved from non-pregnant females show MI at $24 \mathrm{~h}$ and MII at 32-48 h post-IVM (Torner et al., 2003). Further-
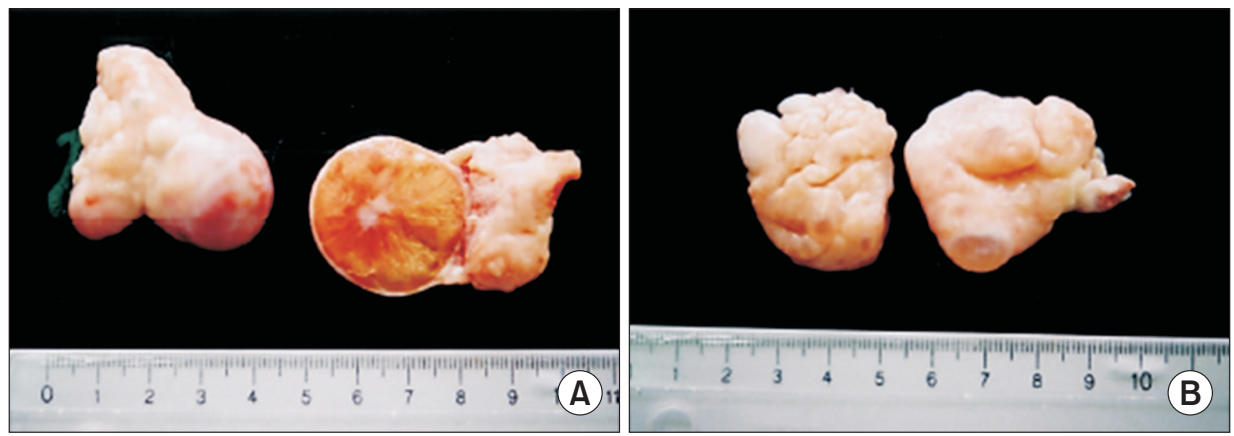

Fig. 1. Ovaries collected from dromedary camel females after slaughter. (A) Ovaries with CL obtained from a pregnant female. (B) Ovaries collected from a non-pregnant female modified from (Moawad, 2005). 
more, the same group reported that the level of apoptotic cells in cumuli of matured COCs increased during IVM, and it was higher in matured COCs from non-pregnant donors for each time point of IVM (Torner et al., 2003). Camel oocytes meiosis during IVM is accompanied by a drastic increase of apoptosis in the surrounding cumulus cells at 0-32 and 0-24 h post-IVM for pregnant and nonpregnant donors, respectively (Torner et al., 2003). The same authors also reported that at $36 \mathrm{~h}$ post-IVM oocytes collected from pregnant females could achieve more than $50 \%$ nuclear maturation rate. However, those obtained from non-pregnant females attain this percentage of nuclear maturation at $32 \mathrm{~h}$ post-IVM (Torner et al., 2003). In our studies, we found that the frequencies of matured dromedary camel oocytes (oocytes at MII stage) significantly decreased in oocytes collected from pregnant animals than those retrieved from non-pregnant ones $(25.0 \%$ vs. $43.7 \%$ ) (Moawad, 2005).

\section{Effect of the breeding season of the female dromedary camel}

Dromedaries are considered seasonal breeders with a relatively short breeding season during the colder months when better pasture conditions prevail (Chen and Yuen, 1979; Wilson, 1984). This observation was based mainly on the seasonal distribution of the birth of the calves, and the status of ovarian activity in slaughtered animals (Novoa, 1970). The breeding season in camel occurs between December and April in Egypt (Shalash, 1965), December and March in Pakistan (Yasin and Wahid, 1957), and from November to April in most of Arabia (Abdel-Rahim and El-Nazier, 1990). Sghiri and Driancourt in 1999 have confirmed the influence of season on ovarian follicular growth and maturation in camels, and they showed that the proportion of females with active ovaries (i.e. with follicles $>5 \mathrm{~mm}$ ) increased from $73.5 \%$ in October/December to $89.0 \%$ in January/May (Sghiri and Driancourt, 1999). Outside of the breeding season, mating activity stops, and the ovaries are inactive or show a limited number of small follicles with irregular or extended follicular wave patterns (Musa and Abusineina, 1978). However, in Egypt, studies showed that the conception of female dromedary can occur at any time of the year (ElWishy and Ghoneim, 1986). In the United Arab Emirates and Saudi Arabia, studies indicated that well-fed females would exhibit limited ovarian activity throughout the summer. Still, the determinant factors of the observed seasonality in conception dates are due to a reduction in the libido of the male as environmental temperatures increase and to the increase in early embryonic death during the hot summer months (Arthur et al., 1985; Skidmore, 2011). Therefore, it is understandable that the breeding season has an impact on oocyte yield, quality and IVM status in dromedary camel. In 2001, a study done by Abdoon in Egypt showed that the number of small (1-3 mm), medium ( $4-9 \mathrm{~mm})$, large $(\geq 10 \mathrm{~mm})$, and the total number of camel ovarian follicles were significantly higher during the breeding season (December to April) than during nonbreeding season (June to October). Furthermore, the total number of recovered and category one oocytes was also higher during the breeding season (6.73 and 5.93 oocytes/ ovary, respectively) than a non-breeding season (5.40 and 4.70 oocytes/ovary, respectively) (Abdoon, 2001). We also assessed the quality of dromedary camel oocytes collected during different months of the year (Moawad, 2005). We found that the recovery rates of oocytes were the lowest (0.78 oocytes/ovary) during August compared to those recovered during the rest of the year (values range from 1.6-3.0 oocyte/ovary). Regarding the quality of oocytes, we noticed that the frequency of grade I oocytes (oocytes with more than three layers of cumulus cells, Fig. 2) was significantly higher during December (32.1\%), January (36.0\%) and February (38.4\%) than during the rest of the year (10.4\%-18.3\%). Also, numbers of selected oocytes for

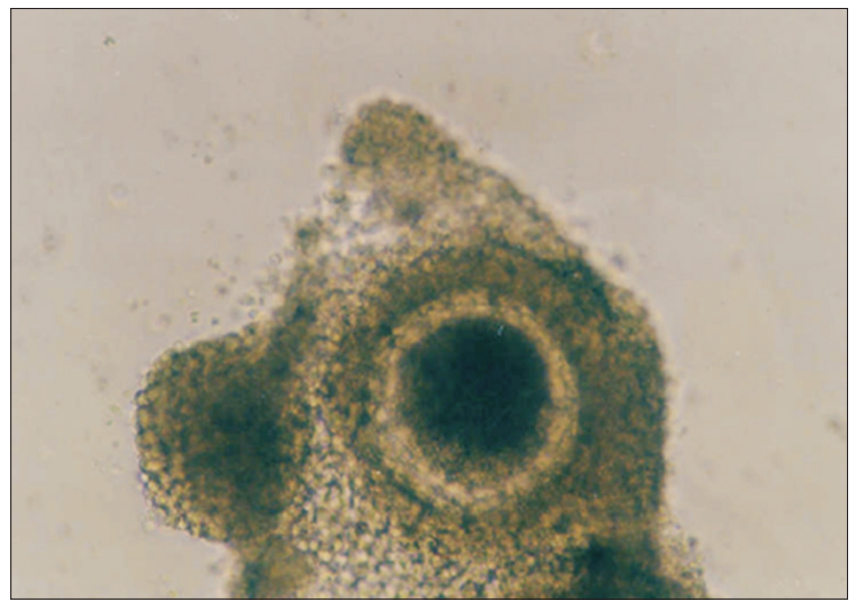

Fig. 2. Dromedary camel cumulus-oocyte complex (COC) with granulated dark cytoplasm and surrounded by more than 3 layers of cumulus cells (Grade 1 COCs) modified from (Moawad, 2005). 
IVM were the highest (100\%) during November, December, January and February but these numbers decreased slightly between August and October (92.2\% to 93.2\%) and reached to the lowest values (75.0\% to $89.6 \%$ ) during March to July. Among the different months, the highest proportions of degenerated oocytes (25.0\%) were seen in July (Moawad, 2005). We also evaluated the variation in IVM rates in relation to the month at which oocytes were collected and the results revealed that proportions of matured oocytes were significantly lower in the groups collected between April and August (values range from $30.0 \%$ to $41.3 \%$ ) than those collected between September and March (47.7\%-58.7\%, Fig. 3 and Fig. 4A, B). When we grouped the data according to the season of the year, we found that the frequencies of oocytes selected for IVM were significantly higher during winter and autumn (100.0\% and $95.9 \%$, respectively) than during summer and

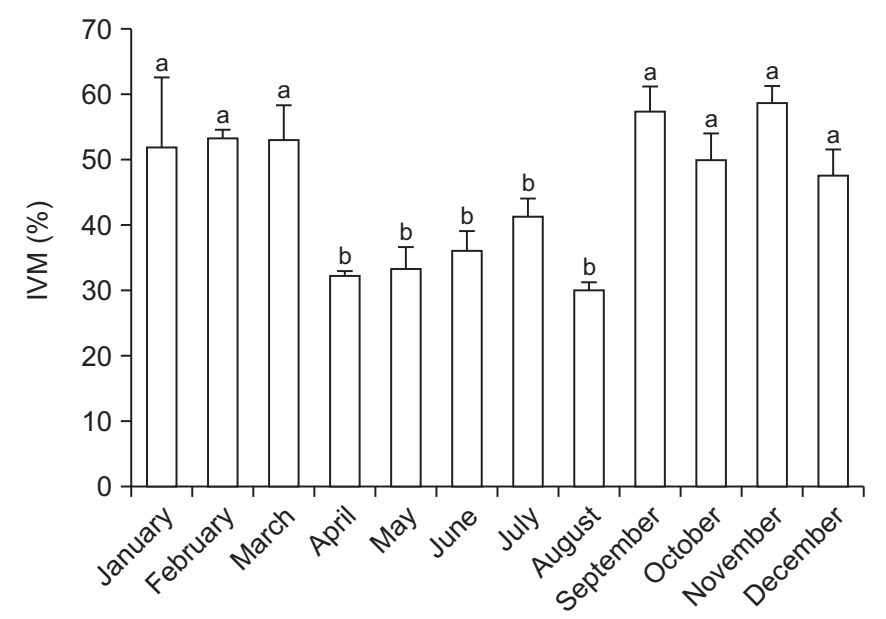

Fig. 3. Effects of the month of the year on IVM rates of dromedary camel COCs. Data are presented as mean \pm SEM. 33-72 oocytes were examined in each experimental group. Different small letters above columns indicate significant differences $(p<0.05)$ by one-way ANOVA. spring ( $82.2 \%$ and $80.6 \%$, respectively). Furthermore, IVM rates were higher in winter and autumn $(54.7 \%$ and $50.6 \%$, respectively) than in summer and spring $(38.6 \%$ and $38.2 \%$, respectively, Fig. 5).

\section{Effect of post-slaughter ovarian storage time}

For in vitro production of domestic animal embryos, most laboratories use oocytes collected from a slaughterhouse, long transport time from the slaughterhouse to the laboratory before culture may adversely affect oocyte quality in terms of nuclear maturation and developmental competence after IVM/IVF (Shioya et al., 1988; Johnston et al., 1989; Moodie and Graham, 1989; Yang et al., 1990; Solano et al., 1994; Schernthaner et al., 1997; Guignot et al., 1999; Yuge et al., 2003; Wongsrikeao et al., 2005; Tellado et al., 2014). In cattle, ovary storage at $37^{\circ} \mathrm{C}$ for 8 h significantly decreased cleavage and blastocyst rates after IVM/IVF/IVC (Yang et al., 1990) and similar results obtained when the ovaries stored at $4^{\circ} \mathrm{C}$ for $12 \mathrm{~h}$ or 24

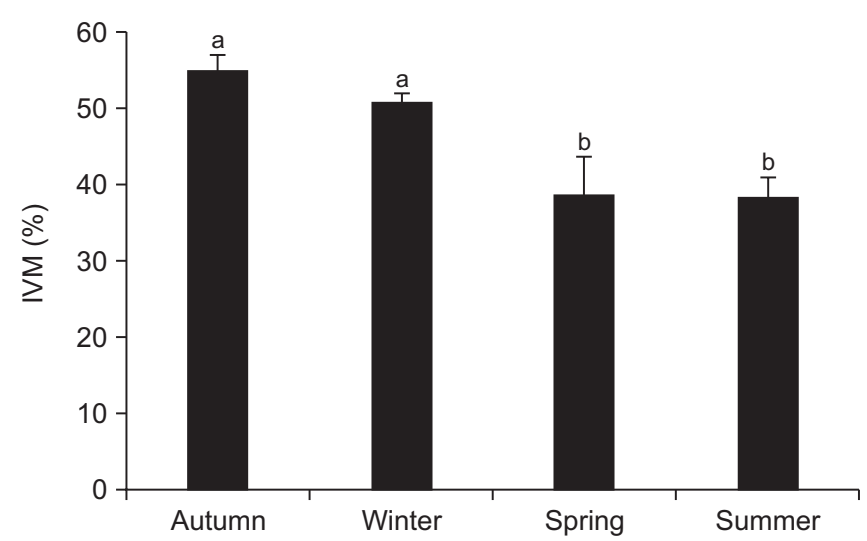

Fig. 5. Effects of season of the year on IVM rates of dromedary camel COCs. Data are presented as mean \pm SEM. 131-164 oocytes were examined in each experimental group. Different small letters above columns indicate significant differences $(p<0.05)$ by one-way ANOVA.
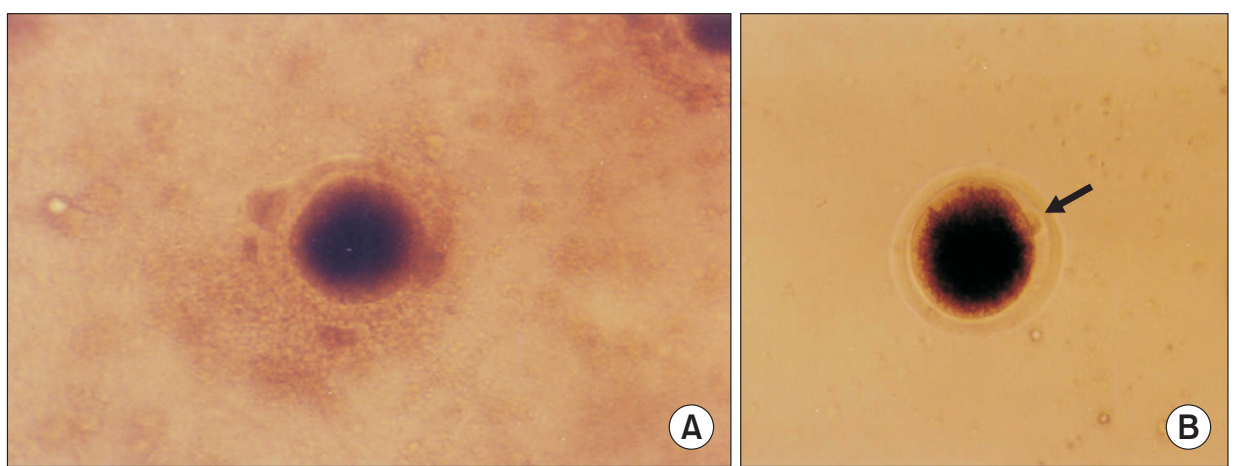

Fig. 4. Dromedary camel oocytes following IVM. (A) IVM oocytes showing an expansion of cumulus cells. (B) IVM oocytes with a first polar body (black arrow) modified from (Moawad, 2005). 
h (Solano et al., 1994). However, another study demonstrated that the storage of bovine ovaries at $15-21^{\circ} \mathrm{C}$ for $24 \mathrm{~h}$ did not significantly affect oocyte maturation, cleavage, and blastocyst production rates (Schernthaner et al., 1997). In horses, a previous study showed that the storage of mare ovaries at $27^{\circ} \mathrm{C}$ to $37^{\circ} \mathrm{C}$ for $6-8 \mathrm{~h}$ did not harmfully affect nuclear maturation and cytoplasmic membrane integrity of the oocytes (Guignot et al., 1999). Though, another study revealed that the storage of mare ovaries at room temperature for 15-18 h resulted in lower maturation rates $(27 \%)$ as compared to the control groups in which oocytes recovered immediately after slaughter (72\%) (Love et al., 2003). In sheep, when ovaries stored at temperatures of $4^{\circ} \mathrm{C}, 22^{\circ} \mathrm{C}$ or $37^{\circ} \mathrm{C}$, oocyte maturation rates decreased with increasing storage time after slaughter, but the oocytes from ovaries stored at $22^{\circ} \mathrm{C}$ showed a higher maturation rate than oocytes stored at the different temperatures (Moodie and Graham, 1989). In pigs, storage of the ovaries at $35^{\circ} \mathrm{C}$ for 6,9 , and $12 \mathrm{~h}$ decreased IVM rates and increased the proportions of oocytes with DNA damage (Wongsrikeao et al., 2005). However, a recent study concluded that the transportation of porcine ovaries at $25^{\circ} \mathrm{C}$ and $35^{\circ} \mathrm{C}$ for $2 \mathrm{~h}$ are the best conditions to maintain adequate oocyte quality, meiotic competence, and IVF rates (Tellado et al., 2014). In buffaloes, a previous study showed that the storage of ovaries at $4^{\circ} \mathrm{C}$ for 4 and $8 \mathrm{~h}$ significantly reduced the quality of oocytes (Ravindranatha et al., 2003). In dromedary camels, we noticed that the storage of ovaries at $25-30^{\circ} \mathrm{C}$ for $4 \mathrm{~h}$ postslaughter did not significantly affect oocyte recovery rates and proportions of oocytes selected for IVM as compared to those stored for 0-30 min. However, the maturation rate tended to be higher for oocytes collected immediately at 0-30 min post-slaughter $(58.9 \%)$ than those obtained at 2-3 hours (47.7\%) or 3-4 hours (47.6\%) post-slaughter (Moawad, 2005). Another study showed that the preservation of dromedary camel ovaries at $25-30^{\circ} \mathrm{C}$ for $5 \mathrm{~h}$ resulted in a recovery rate of 12.4 oocytes/ovary, and this value decreased to 7.1 oocytes/ovary by increasing the time of ovarian storage to $24 \mathrm{~h}$ (Abdel-Khalek et al., 2010). Furthermore, the highest proportion of good quality oocytes with compact cumulus cells (65\%) was reported at $5 \mathrm{~h}$ preservation time than those stored at $6,7,9,12$ and 24 h $(54.0 \%, 50.4 \%, 48.5 \%, 42.1 \%$ and $34.0 \%$, respectively) (Abdel-Khalek et al., 2010). Taken together, it seems that preservation of dromedary camel ovaries at $25-30^{\circ} \mathrm{C}$ for
4-5 h did not negatively impact oocyte quality and IVM rates.

\section{Effect of IVM media}

The type of IVM medium and its supplements play a crucial role in maturation status and subsequent embryo development after IVF (Rose and Bavister, 1992). IVM media are categorized into simple and complex media. Simple media are usually bicarbonate buffered systems that contain physiological saline with pyruvate, lactate, and glucose, and they differ in their ion and energy source concentrations. Complex media include in addition to the essential components of simple media, amino acids, vitamins, and purines. Various media have been developed for IVM of oocytes in different mammalian species. These media include TCM-199 (Rose and Bavister, 1992; Ghoneim, 1999; Kafi et al., 2002; Mahmoud et al., 2003; Torner et al., 2003; Khatir et al., 2004, 2005; Moawad, 2005; Khatir and Anouassi, 2006; Wani, 2009; Wani et al., 2010; Moawad et al., 2011; Moawad et al., 2012a; Moawad et al., 2012b; Fathi and El-Shahat, 2017; Fathi et al., 2018), minimum essential medium (MEM) (Ravindranatha et al., 2001), and Ham's F-10 (Totey et al., 1993; Moawad, 2005; Tamilmani et al., 2005; Zeidan et al., 2011). In most IVF laboratories, TCM-199 is considered the most common medium used for IVM; this is because TCM-199 contains some factors in its composition such as essential amino acids and glutamine that stimulate DNA and RNA synthesis and improve cell division (Pawshe et al., 1994). Previous studies showed that maturation of bovine oocytes in SFRE, TCM-199, and MEM essential media significantly improved 2-cell embryo development (72-82\%) after IVF than those matured in Waymouth and Ham's F-12 media $(50.0 \%$ and $35.0 \%$, respectively) (Bavister et al., 1992). Till now, the maturation conditions used in IVM of dromedary camel oocytes have been adopted from those used in other domestic species; however, the species differences can influence the maturation outcomes (Edwards, 1965). TCM-199 and Ham's F-10 were previously used for oocyte maturation in dromedary camels (Ghoneim, 1999; Kafi et al., 2002; Mahmoud et al., 2003; Torner et al., 2003; Khatir et al., 2004; Moawad, 2005; Wani and Wernery, 2010; Moawad et al., 2012a; Fathi et al., 2014; Fathi et al., 2018). Few studies have compared the effect of different maturation media on IVM rates in dromedary camels. We examined 
the impact of using TCM-199 or Ham's F-10 as maturation media on IVM rates of dromedary camel oocyte, and we did not find a significant effect on the frequencies of matured oocytes ( $45.2 \%$ vs. $40.3 \%$, respectively) (Moawad, 2005). Previous studies showed that IVM of camel oocytes in TCM-199 medium resulted in a higher maturation rate (61\%) than those matured in CMRL (50\%) or CR1 (47\%) media (Nowshari, 2005). A recent study demonstrated that IVM of dromedary camel oocytes during the breeding season in TCM-199 or Hank's media significantly increased the proportions of matured oocytes $(68.2 \%$ and $62.5 \%$, respectively) compared to those cultured in basal medium (52.6\%) or Ham's-F10 (53.6\%) (Zeidan et al., 2011). However, during the non-breeding season, the highest IVM rates were achieved in Ham's-F10 (51.7\%) than those reported in the other media (values ranged from $20.0 \%$ to 44.4\%) (Zeidan et al., 2011). In conclusion, these results confirm the critical impact of the type of maturation media on the success rates of IVM in dromedary camel.

\section{Effect of media supplements}

The components of maturation media and culture conditions can affect and even modulate the meiotic regulation of mammalian oocytes (Kito et al., 1997; Kito and Bavister, 1997). Culture conditions for IVM in domestic species have been improved in recent years, such that nowadays, a large percentage of oocytes complete nuclear maturation (Lonergan and Fair, 2016). Various supplements such as serums, follicular fluid (FF), hormones, epidermal growth factors (EGF), antioxidants, caffeine, Lcarnitine (LC), retinoic acid (RA), and others have been successfully used during IVM to improve the outcomes of IVP in different species including dromedary camel.

\section{1) Effect of serum}

Different protein sources such as serum and bovine serum albumin (BSA) have been incorporated in culture media, besides having nutritive value, the serum has many other support functions for oocyte maturation and embryo development. For example, it prevents the hardening of zona pellucida (ZP), which could adversely impact fertilization (Downs et al., 1986). Fetuin, a significant glycoprotein component of fetal calf serum (FCS), can prevent the hardening of ZP by blocking the action of proteolytic enzymes arising from premature release of cortical granules and subsequent improve the fertiliza- tion outcomes (Schroeder et al., 1990). Furthermore, the serum also has antioxidant effects, and this occurs by reducing the formation of superoxide (Kan and Yamane, 1983). Moreover, the serum is considered a source of albumin, which is essential in regulating the osmolality of the media (Thompson, 2000). Various studies examined the effects of type of the serum during IVM on oocyte maturation and embryo development in different species, including dromedary camels. For example, we noticed that the inclusion of $10 \%$ of either FCS, newborn calf serum (NBCS), or non-pregnant camel serum (NPCS) during camel IVM improved nuclear maturation than those matured in serum-free media (Fig. 6) (Moawad, 2005). However, a previous report showed that maturation of camel oocytes in IVM media supplemented with either $10 \%$ FCS or $10 \%$ pregnant camel serum (PCS) did not affect maturation rates (Mahmoud et al., 2003). Another study reported similar IVM rates (nearly $72 \%$ ) for camel oocytes matured in IVM media supplemented with either FCS, estrus dromedary serum (EDS), and BSA (Wani and Wernery, 2010). A comparison between the effect of supplementation of IVM media with $10 \%$ FBS or with $10 \%$ camel FF on cumulus expansion and nuclear maturation of dromedary camel oocytes has been recently reported (Yaqoob et al., 2017). The results showed that FF supplementation improved cumulus expansion (grade 2, all COCs were completely expanded) and showed a widening of the intercel-

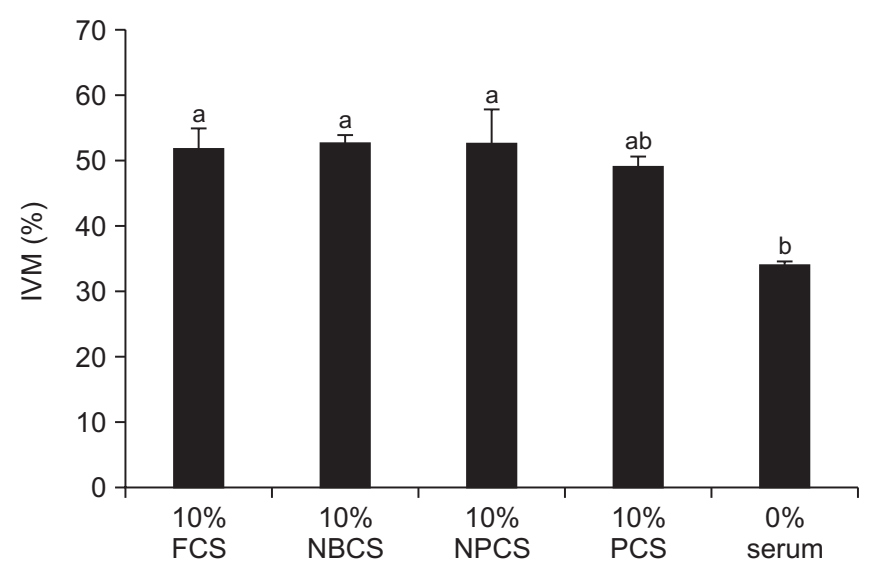

Fig. 6. Effects of serum supplementation to IVM medium (TCM199) on IVM rates of dromedary camel COCs. FSC (fetal calf serum), NBCS (newborn calf serum), NPCS (non-pregnant camel serum), PCS (Pregnant camel serum). Data are presented as mean \pm SEM. 45-65 oocytes were examined in each experimental group. Different small letters above columns indicate significant differences $(p<0.05)$ by one-way ANOVA. 
lular spaces among cumulus cells when compared with FBS. However, there were no differences in polar body extrusion rates, embryo cleavage, and subsequent embryo development (Yaqoob et al., 2017). These results were explained based on FF contains several undefined growth factors affecting cumulus cell function (Daen et al., 1994; Yaqoob et al., 2017).

\section{2) Effect of hormones}

Various hormones such as follicle-stimulating hormone (FSH), LH, and estradiol $\left(\mathrm{E}_{2}\right)$ have been included during IVM to improve oocyte maturation rates and subsequent embryo development in different mammalian species (Moor and Trounson, 1977; Fukushima and Fukui, 1985; Zuelke and Brackett, 1990; Totey et al., 1992; O'Brien et al., 1994; Nagai et al., 2000). Gonadotropins (FSH and LH) stimulate cumulus cells to synthesize molecules capable of initiating GVBD (Tsafriri et al., 2005). Furthermore, FSH is the primary hormone responsible for cumulus cell expansion and subsequent improvement in sperm penetration and fertilization process (Eppig, 1979a, 1979b; Pandey et al., 2010). A previous study demonstrated that LH could change calcium distribution within the ooplasm and subsequently can promote glycolysis, combined with high levels of mitochondrial glucose oxidation within bovine COCs (Bevers et al., 1997). It was also evident that exposure of oocytes to LH during IVM increased glutamine metabolism (Abd EL-Aziz et al., 2016). On the other hand, other reports showed no positive effect of LH supplementation to IVM media on bovine embryo development (Keefer et al., 1991). Studies revealed that mRNA of the LH receptors was detected exclusively in thecal cells and not in the oocyte confirming the later results (Bevers et al., 1997). $E_{2}$ is known to improve the completion of maturational changes and also to support the synthesis of presumed male pronuclear growth factor (Fukui and Ono, 1989). Addition of LH or FSH to bovine IVM medium contains $\mathrm{E}_{2}$ increased the proportion of matured oocytes to reach to 4-8 cell stages after IVF (20.0\% for $\mathrm{LH} / \mathrm{E}_{2}$ and $15.4 \%$ for $\mathrm{FSH} / \mathrm{E}_{2}$ ) when compared to the control group without hormone supplementation $(5.7 \%)$ or with those supplemented with $E_{2}$ alone (6.7\%) (Younis et al., 1989). Supplementation of IVM medium with FSH or with equine chorionic gonadotropin (eCG) significantly increased cleavage and blastocyst rates in buffalo oocytes when compared with the control group (Abdoon et al., 2001). In dromedary camel, we found that supplementation of IVM medium with FSH and LH at a concentration of $10 \mu \mathrm{g} /$ $\mathrm{mL}$ each significantly increased IVM rates as compared to those matured in a medium supplemented with LH only at $150 \mu \mathrm{g} / \mathrm{mL}$ (51.0\% vs. 26.2\%) (Moawad, 2005).

EGF is known to promote oocyte nuclear maturation rates in different mammalian species (Dekel and Sherizly, 1985; Das et al., 1992; Goud et al., 1998; Rieger et al., 1998; Shimada et al., 2006; Chen and Downs, 2008; Akaki et al., 2009; Ben-Ami et al., 2011; Richani et al., 2013). EGF induces its action by disrupting the communication between the oocyte and the surrounding cumulus cells (Dekel and Sherizly, 1985), creating a positive maturational signal (Downs, 1989) and affecting tyrosine kinase-dependent intracellular mechanism (Lorenzo et al., 2001). EGF induces oocyte maturation in explanted whole follicles (Dekel and Sherizly, 1985), and isolated COCs meiotically arrested by cAMP modulators (Downs et al., 1988). FSH-induced oocyte meiotic resumption and cumulus expansion in vitro are mediated by the EGF-like peptides (Procházka et al., 2011). Exposure of COCs to high levels of cAMP, a downstream effector of FSH, also induces meiotic resumption by upregulation of EGF-like peptides (Shimada et al., 2006). Previous study revealed that supplementation of IVM media with $20 \mathrm{ng} / \mathrm{mL}$ EGF improved nuclear maturation rates of dromedary oocytes compared with those matured in medium supplemented with $10 \mathrm{ng} / \mathrm{mL}$ and $0 \mathrm{ng} / \mathrm{mL}$ EGF ( $81.4 \%$ vs. $66.9 \%$ and 67.2\%, respectively) (Wani and Wernery, 2010). A recent study was done also in dromedary camels has confirmed these findings and reported $87.9 \%$ maturation rates in 20 $\mathrm{ng} / \mathrm{mL}$ EGF supplemented group compared to $77.9 \%$ in EGF non-supplemented group (Hemeida et al., 2015).

\section{3) Caffeine}

Caffeine (1,3,7-trimethylxanthine), a phosphodiesterase inhibitor, has been reported to induce dephosphorylation of Y-15 and T14 of p34cdc2. This effect occurs by inhibition of Myt1/Wee1 kinase (Smythe and Newport, 1992). The effect produced by caffeine results in an increase in the activity of MPF in cultured mammalian cells, Xenopus, and porcine oocytes (Steinmann et al., 1991; Smythe and Newport, 1992; Kikuchi et al., 2000; Xia et al., 2000). In sheep, previous studies showed that treatment of IVM oocytes with caffeine increased the activities of both MPF and MAPK, improved frequencies of nuclear envelope 
breakdown and chromosome condensation of transferred nuclei, increased total cell numbers, and reduced the rate of apoptotic nuclei in blastocysts produced by SCNT (Lee and Campbell, 2006; Choi and Campbell, 2010; Moawad et al., 2018). Moreover, in aged denuded ovine oocytes, caffeine treatment increased the blastocyst development rates and decreased the frequency of polyspermy following IVF (Maalouf et al., 2009). A recent study showed that culturing dromedary camel oocytes in IVM medium without caffeine for 24 hours and then in a medium supplemented with $10 \mathrm{mM}$ caffeine for 6 hours during 30 hour IVM significantly improved maturation, fertilization, and preimplantation embryo development rates (Fathi et al., 2014). These findings are crucial for the refinement of IVM conditions that subsequently can improve the efficiency of IVP in camelids (Fathi et al., 2014).

4) L-carnitine (LC)

LC; $\beta$-hydroxy- $\gamma$-trimethylammonium-butyric acid, a small water-soluble molecule, is known to play an essential role in fatty acid metabolism. This molecule is crucial for standard mitochondrial oxidative processing of fatty acids and the release of acyl-COA esters. Consequently, it influences ATP levels in the cells (reviewed by [Dunning and Robker, 2012]). It also has an antioxidant activity to protect the cells from DNA damage (Abdelrazik et al., 2009). The beneficial effects of LC on embryonic development in culture have been reported in many mammalian species. In mice, supplementation of the IVM medium with LC improved spindle microtubule assembly and chromosome alignment in MII oocytes, and it increased subsequent embryonic development through reduction of apoptosis (Mansour et al., 2009; Dunning et al., 2010; Moawad et al., 2013; Moawad et al., 2014). In cattle, LC promotes the relocation of active mitochondria to the inner oocyte membrane and, thus, enhances preimplantation embryo development (Yamada et al., 2006). Moreover, LC supplementation to IVC media improved lipid metabolism in cattle embryos and increased the cryotolerance of blastocysts (Takahashi et al., 2013). In pigs, LC promotes nuclear maturation in oocytes and increases cleavage rates, which are associated with an enhancement in mitochondrial activity and a decrease in intracellular lipid contents and $\mathrm{H}_{2} \mathrm{O}_{2}$ levels (Somfai et al., 2011). Recently in dromedary camel, it has been shown that supplementation of IVM medium with $0.5 \mathrm{mg} / \mathrm{mL} \mathrm{LC}$ significantly improved nuclear maturation rates (74.7\%) than those supplemented with 0.25 or $1.0 \mathrm{mg} / \mathrm{mL} \mathrm{LC}$ (63.9\% and 59.7\%, respectively) and those in the control group (60.2\%) (Fathi and El-Shahat, 2017).

\section{5) Retinoic acid (RA)}

RA, a metabolite of vitamin A (retinol), incorporates in many functions related to vitamin A such as cell growth, development, and differentiation, and has been implicated in reproductive processes including folliculogenesis and embryonic survival (Morriss-Kay and Ward, 1999). The critical role of RA during IVM has been extensively studied in many species include camels (Ikeda et al., 2005; Atikuzzaman et al., 2011; Nasiri et al., 2011; Liang et al., 2012; Pu et al., 2014; Saadeldin et al., 2019). It has been shown that RA can promote cytoplasmic maturation through its modulatory effects on the expression of genes encoding gonadotrophin receptors, midkine, cyclooxygenase 2 , and nitric oxide synthase in cumulus-granulosa cells (Ikeda et al., 2005; Liang et al., 2012). RA has also been reported to diminish apoptosis in COCs (Liang et al., 2012; Pu et al., 2014); besides, RA may enhance cumulus expansion (Atikuzzaman et al., 2011). Moreover, RA acts as an antioxidant by reducing the levels of reactive oxygen species and oxidative stress during oocyte maturation (Ikeda et al., 2005; Livingston et al., 2009). In dromedary camel, it has been shown that supplementation of IVM medium with $20 \mu \mathrm{M}$ RA significantly reduced the proportion of degenerated oocytes and significantly improved oocyte meiosis and first polar body extrusion compared to the control $(0 \mu \mathrm{M})$ and other RA supplemented groups (10 and $40 \mu \mathrm{M})$ (Saadeldin et al., 2019). Furthermore, in the same study, the authors reported that RA significantly reduced the mRNA transcript levels of apoptosis-related genes, including $B A X$ and $P 53$, and reduced the $B A X / B C L 2$ ratio (Saadeldin et al., 2019). Besides, RA significantly decreased the expression of the transforming growth factorbeta (TGF $\beta$ ) pathway-related transcripts associated with the actin cytoskeleton, ACTA2, and TAGLN; however, RA increased TGF $\beta$ expression in cumulus cells (Saadeldin et al., 2019). These results highlight the beneficial effects of RA on camel oocyte IVM.

\section{Effects of cumulus cells and duration of IVM}

Intracellular communication between the cumulus cells and the oocyte is essential for numerous processes dur- 
ing oocyte maturation (Sutton et al., 2003). The cumulus cells are a sub-population of ovarian granulosa cells and comprised the corona radiata, which represented the layers closest to the oocyte and generally in close contact through cytoplasm extensions across the ZP and outer cumulus which communicates with the corona through gap junctions (de Loos et al., 1991). Cumulus cells provide nutrients to the oocytes during their growth; they also participate in the zona formation and in the synthesis of proteins and hyaluronic acids, which are essential in the transportation of the sperm in the oviduct during the process of fertilization (Bedford and Kim, 1993). The positive effect of cumulus cells on oocyte maturation and development has been reported in cattle and other species (Konishi et al., 1996). In buffalo, the importance of the cumulus cells during oocyte maturation was confirmed when COCs were denuded off their surrounding cumulus cells and allowed them to grow in vitro, only $41 \%$ of such oocytes could reach to MII stage (Datta and Goswami, 1999). However, when these good quality but artificially denuded oocytes were cultured along with extra cumulus cells, the maturation rate increased to 70\% (Datta and Goswami, 1999). The ultrastructural and morphological characteristics of cultivable dromedary camel oocytes were studied by (Nili et al., 2004; Kafi et al., 2005). They recorded that the $\mathrm{COC}$ is a multi-layered investment of compact pale dark and semi-dark cells. Most cumulus cells are polygonal; however, some are round and elongated. The intercellular junctions between COCs are desmosome; cumulus cell projections were observed throughout $\mathrm{ZP}$ and ended in the invagination of the oolemma (Nili et al., 2004; Kafi et al., 2005). Previous studies showed that, most of camel oocytes with compact (55.0\%-56.5\%) and dispersed (58.4\%-60.0\%) cumulus were immature at diplotene stage at the time of recovery, and both COC types contains a similar proportion of immature oocytes (Torner et al., 2003). In our studies, we noticed that IVM of dromedary camel oocytes in the presence of cumulus cells significantly increased the maturation rate (60.3\%) as compared with those matured in the absence of cumulus cells (denuded oocytes) (38.2\%) (Moawad, 2005).

Regarding the duration required for IVM, in llamas, previous studies showed that at the time of oocyte recovery, $41.6 \%$ of the recovered oocytes were immature, i.e., at GV, GVBD, MI stage, $6.3 \%$ were at MII stage, and $52.1 \%$ have degenerated (Del Campo et al., 1994b). After 30 h of
IVM, the maturation rate reached up to 30.4\% (Del Campo et al., 1994b). In dromedary camels, another study recorded maturation rates of $17.4 \%(4 / 23)$ and $16.6 \%(6 / 36)$ after $24 \mathrm{~h}$ IVM for oocytes obtained from pregnant and non-pregnant females, respectively (Ghoneim, 1999). In 2001, Abdoon observed that IVM of dromedary camel oocytes for $36 \mathrm{~h}$ resulted in high percentages of cumulus expansion (92.0\%) and nuclear maturation rates (85.4\%) (Abdoon, 2001). The same author also added that increasing IVM time to 48 and $72 \mathrm{~h}$ increased the percentage of degenerated oocytes (21.6 and 29.0\%, respectively) (Abdoon, 2001). In 2002, Kafi and colleagues found that, after $6 \mathrm{~h}$ IVM, $40 \%$ of dromedary camel COCs showed complete expansion of cumulus cells, and the degree of expansion increased significantly at $30 \mathrm{~h}$ IVM (Kafi et al., 2002). Based on cytogenetic evaluation the same authors found that $87 \%$ of oocytes were at GV stage at the time of aspiration $(0 \mathrm{~h}), 66 \%$ at GVBD at $6 \mathrm{~h}$ culture time, progression to MI (48\%) and MII (71\%) occurred at 18 and $42 \mathrm{~h}$, respectively (Kafi et al., 2002). The peak rate of polar body extrusion (71\%) occurred at $42 \mathrm{~h}$, which was comparable to $66.0 \%$ at $30 \mathrm{~h}$ (Kafi et al., 2002). In 2003, a study published by Mahmoud and colleagues showed that at $24 \mathrm{~h}$ post-IVM $14.8 \%, 11.7 \%, 7.8 \%$, and $35.9 \%$ of dromedary camel oocytes were at GVBD, MI, anaphase I and telophase I (AI/ TI), and MII, respectively (Mahmoud et al., 2003). Besides, at $24-30 \mathrm{~h}$ post-IVM, the proportions of AI/TI gradually decreased, followed by degeneration at $48 \mathrm{~h}$ (Mahmoud et al., 2003). In the same study, the authors recorded that the maximum proportion of MII was achieved at 30$36 \mathrm{~h}$ (42.37\% and $41.66 \%$, respectively) (Mahmoud et al., 2003). Forty-eight hours post maturation; all metaphases were undefined due to the degeneration of chromatin (Mahmoud et al., 2003). Torner et al. (2003) reported that the oocytes collected from ovaries of pregnant camels require $36 \mathrm{~h}$ IVM time to reach levels of more than $50 \%$ MII in comparison to $32 \mathrm{~h}$ for oocytes collected from the ovaries of non-pregnant animals. Wani and Nowshari (2005) studied the chronological consequences during camel oocytes IVM from 0 to $48 \mathrm{~h}$, and they found that $75.4 \%$ of oocytes were at GV stage at the start of maturation; however, none of the oocytes revealed GV stage at $28 \mathrm{~h}$ of maturation (0/97). At $8 \mathrm{~h}$ of maturation, $49.3 \%$ of the oocytes were at diakinesis, and after $16 \mathrm{~h}, 50 \%$ were at the MI stage (Wani and Nowshari, 2005). At $24 \mathrm{~h}$, the maximum number of oocytes was at anaphase, and at 44 
$\mathrm{h}$, the maximum number of oocytes $(52.0 \%)$ was at the MII stage (Wani and Nowshari, 2005). After 48 h, the proportion of oocytes with no visible chromatin increased to $52.9 \%$, and the proportion of MII oocytes decreased to $37.6 \%$ (Wani and Nowshari, 2005). The authors concluded that 40-44 h maturation time yielded the highest proportion of mature oocytes (Wani and Nowshari, 2005). Khatir et al. (2004) recorded that at 36 h IVM of dromedary camel oocytes, $63 \%$ of oocytes were at MII stages as characterized by the presence of MII plate and the first polar body. In our studies we found that maturation of dromedary camel oocytes for $36 \mathrm{~h}$ resulted in significantly higher nuclear maturation rate $(72.3 \%)$ than those matured for $24 \mathrm{~h}$ (47.6\%) or $48 \mathrm{~h}$ (45.2\%); however, these values did not significantly differ from those matured for 30 h (58.1\%, Fig. 7) (Moawad, 2005). Recently, camel COCs were cultured for different durations $(28,32,36,42$, and $48 \mathrm{~h}$ ) to determine the optimal oocyte nuclear maturation duration required for supporting early embryonic development (Yaqoob et al., 2017). The results revealed that COCs cultured for $28 \mathrm{~h}$ showed reduced cumulus expansion when compared with those cultured for 32 and 36 h; however, first polar body extrusion and nuclear maturation showed no difference among the three groups (55.7\% to $60.0 \%$ ) (Yaqoob et al., 2017). Interestingly, the groups cultured for 42 and $48 \mathrm{~h}$ displayed two polar bodies extrusion in the perivitelline space in $43.1 \%$ and $54.3 \%$ of the examined oocytes, respectively (Yaqoob et al., 2017). Spontaneous parthenogenesis of camel oocytes cultured

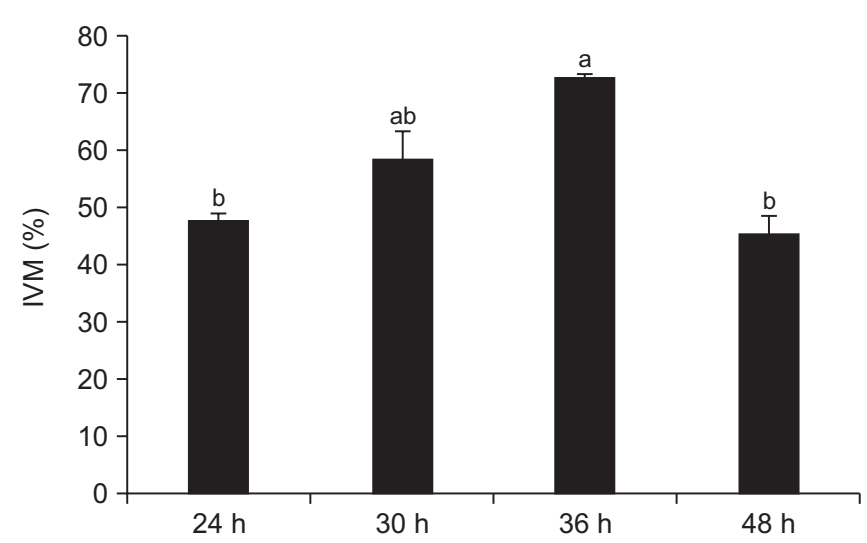

Fig. 7. Effects of duration of IVM on maturation rates of dromedary camel COCs. Data are presented as mean \pm SEM. 42-65 oocytes were examined in each experimental group. Different small letters above columns indicate significant differences $(p<$ $0.05)$ by one-way ANOVA. for long periods have been reported in few studies. For example, culturing dromedary camel oocytes for $48 \mathrm{~h}$ resulted in development of 2-cell stages embryos (Kafi et al., 2005). Furthermore, another study reported that $1.2 \%$ of camel oocytes develops to 2-8 cell stage embryos after $40 \mathrm{~h}$ of IVM (Abdoon et al., 2007). These results indicated that culturing of dromedary camel oocytes for a prolonged period allows oocyte to initiate meiosis II and that some oocytes complete meiosis II and can undergo spontaneous cell division (Yaqoob et al., 2017).

\section{IN VITRO FERTILIZATION}

Fertilization is a complex process of cell to cell interaction, which starts with specific recognition and binding of spermatozoa to oocytes and ultimately leads to the fusion of male and female pronuclei (Dale, 1987). In IVF systems, sufficient maturation of the spermatozoa is of the same importance as oocyte maturation (Xu et al., 1996). Sperm must undergo dramatic changes before fertilization; first, the sperm must be capacitated, and second, the sperm must undergo an acrosome reaction (AR) (Ball et al., 1984). Capacitation of mammalian spermatozoa was first identified by (Austin, 1951; Chang, 1951), and it happens in vivo in the uterine or oviductal lumen (Chang, 1951). Once spermatozoon has been capacitated, it displays typical hyperactive motility and later an AR (Samper et al., 1989). AR, an exocytic event, initiated immediately after binding of the sperm to the oocyte. The sperm plasma membrane fusses to the underlying acrosomal membrane at multiple sites, and the acrosomal contents are released. The hydrolytic enzymes released are required to dissolve the ZP matrix around the penetrating sperm and allow the sperm to enter the perivitelline space (Gadella et al., 2001). However, if the acrosome reaction is initiated too early (i.e., prior to ZP binding) the enzymes will be lost and the sperm lose its ability to penetrate the ZP and to complete the fertilization process (Gadella et al., 2001). The earliest successful results of IVF obtained by using spermatozoa capacitated in vivo were reported in rabbits (Chang, 1959) and mice (Whittingham, 1968). In vitro capacitation of mammalian spermatozoa has been accomplished in several species, including humans (Yanagimachi et al., 1976), bulls (Iritani et al., 1984), and stallions (Samper et al., 1989). However, little is known about capacitation and AR of spermatozoa in camelid (Moawad, 2005; 
Moawad et al., 2012a; Crichton et al., 2015).

\section{Factors affecting IVF rates}

1) Sperm capacitating agents

It has been demonstrated that exposure of bovine semen to high ionic strength media (HIS) induced sufficient capacitation for sperm to fertilize in vivo matured oocytes (Brackett et al., 1982). The HIS medium was made by adding enough $\mathrm{NaCl}$ to the Bracket-Oliphant medium (BO) (Brackett and Oliphant, 1975) to achieve 380 mosmols. The HIS and BO media had previously been shown to induce capacitation of rabbit sperm by presumably displacing decapacitation factors from the surface of sperm (Brackett and Oliphant, 1975). Treating either fresh or frozen-thawed bovine sperm with HIS treatment for IVF produced only modest penetration rates of oocytes by sperm (Parrish, 2014). A different approach for capacitating bovine spermatozoa was also being developed by Ball et al. (Ball et al., 1983), and related to the possible role that follicular fluid and oviduct secretions play in sperm capacitation or inducing the AR. Follicular fluid and oviduct secretions are abundant in glycosaminoglycans (GAGs) (Lee and Ax, 1984), and sperm were able to undergo the AR after exposure to these compounds (Ball et al., 1983). Heparin, as commercially available sulfated GAGs, is known to induce capacitation and AR of bovine spermatozoa (Lenz et al., 1983). Heparin induces its capacitating effect through binding to a series of bovine seminal plasma proteins (BSPs) that bind to epididymal sperm at ejaculation leading to changes to sperm intracellular $\mathrm{pH}\left(\mathrm{pH}_{\mathrm{i}}\right)$, intracellular calcium $\left(\mathrm{Ca}_{\mathrm{i}}\right)$, and cAMP levels (Parrish, 2014). Use of heparin as a capacitating agent has been reported in many species including camels (Parrish et al., 1986; Lu et al., 1987; Bavister et al., 1992; Totey et al., 1992; Khatir et al., 2004; Moawad, 2005; Moawad et al., 2012a; Parrish, 2014). Caffeine: a phosphodiesterase inhibitor; another compound is also known to induce capacitation in mammalian spermatozoa by increasing cAMP and $\mathrm{Ca}_{\mathrm{i}}$ levels inside the spermatozoa (Aoyagi et al., 1988). In addition to its effect as a capacitating agent, caffeine also enhances sperm motility (Garbers et al., 1971). The use of caffeine in inducing in vitro sperm capacitation has been demonstrated in different species (Niwa and Ohgoda, 1988; Totey et al., 1992; Bou et al., 1993; Moawad, 2005; Moawad et al., 2012a). Other compounds such as calcium ionophore A23187 and theophylline have also been used for induction of sperm capacitation and AR in vitro (Yang et al., 1993; Kawakami et al., 1999; Kitiyanant et al., 2002; Moawad, 2005; Moawad et al., 2012a). Several studies have shown that calcium ionophore A23187 induces its effect by increasing $\mathrm{Ca}_{\mathrm{i}}$ concentration excessively (Visconti et al., 1999), however, theophylline a methylxanthine derivative has the ability to elevate cAMP and cAMP-dependent processes of sperm, including motility, capacitation and AR (Glogowski et al., 2002). In camelids, previous study demonstrated that insemination of IVM Bactrian camel oocytes with epididymal spermatozoa treated with caffeine and BSA for $2 \mathrm{~h}$ produced $43 \%$ fertilization rate (Bou et al., 1993). Del Camp et al. (1994b) treated four different groups of matured llama oocytes with different concentrations of heparin for IVF, namely; COCs treated with $2 \mu \mathrm{g} / \mathrm{mL}$ heparin (group 1), COCs treated with $5 \mu \mathrm{g} /$ $\mathrm{mL}$ heparin (group 2), denuded oocytes treated with $2 \mu \mathrm{g} /$ $\mathrm{mL}$ heparin (group 3), and denuded oocytes treated with $5 \mu \mathrm{g} / \mathrm{mL}$ heparin (group 4). They inseminated each group with $2-3 \times 10^{6}$ epididymal sperm cell $/ \mathrm{mL}$ and recorded similar fertilization rates (29.2\%) in the four groups. However, the frequency of normal fertilization rate (oocyte with 2 pronuclei) was greater in denuded oocytes (67.7\%) than in COCs (36.0\%) regardless of heparin concentration (Del Campo et al., 1994b). Khatir et al. (2004) inseminated 1135 camel COCs with ejaculated fresh camel semen at a final concentration of $0.5 \times 10^{6}$ sperm cell $/ \mathrm{mL}$ in $\mathrm{F}-$ TALP medium supplemented with $10 \mu \mathrm{g} / \mathrm{mL}$ heparin and recorded $68 \%$ penetration rate, $52 \%$ normal fertilization rate, and 34\% polyspermic fertilization. Beside capacitating agents, types and supplements of IVF media can affect fertilization rates. We found that supplementation of IVF media (F-TALP) with $6 \mathrm{mg} / \mathrm{mL}$ BSA significantly improved fertilization rates of IVM dromedary camel oocytes than those inseminated in F-TALP supplemented with $3 \mathrm{mg} / \mathrm{mL}$ polyvinyl alcohol (PVA; $52.4 \%$ vs. 28.6\%) (Moawad, 2005; Moawad et al., 2012a). Beneficial effects of BSA on sperm capacitation and IVF have been reported in many studies (Eckert and Niemann, 1995; Parrish, 2014).

\section{2) Camel epididymal sperm and IVF}

IVF of oocytes with epididymal spermatozoa has been applied in different species included cattle (Goto et al., 1989), pig (Rath and Niemann, 1997), cat (Niwa et al., 1985); llama (Del Campo et al., 1994b), Bactrian and 
dromedary camels (Bou et al., 1993; Moawad, 2005; Wani, 2009; Moawad et al., 2012a; Fathi et al., 2014; Scholkamy et al., 2016; Abdelkhalek et al., 2017; Fathi and El-Shahat, 2017; Fathi et al., 2018). Many factors have been reported to affect the fertilization rates of epididymal spermatozoa in dromedary camel include the site of semen collection, age of the animals and their use in natural or artificial breeding, methods of semen preparation, sperm concentration, and developmental competence of the oocytes (Wani, 2009). It has been shown that the fertilization of matured dromedary camel oocytes with epididymal spermatozoa resulted in 52\%-67\% IVF rates (Wani, 2009). In our studies we were able to report 55.5\%, 62.5\%, 62.7\% and $47.2 \%$ total fertilization rates following IVF of matured dromedary camel oocytes with epididymal spermatozoa at concentrations of $1,2,3$, or $4 \times 10^{6}$ sperm cell $/ \mathrm{mL}$, respectively (Moawad et al., 2012a). We also found that the proportions of fertilized oocytes with 2 pronuclei were higher in oocytes inseminated with $2 \times 10^{6}$ sperm cell/ $\mathrm{mL}$ (29.7\%) than those inseminated with $4 \times 10^{6}$ sperm cell/mL (11.1\%) (Moawad, 2005; Moawad et al., 2012a). We also reported that treatment of epididymal camel spermatozoa with $5 \mathrm{mM}$ caffeine before IVF significantly improved fertilization rates compared with those treated with $1 \mathrm{mM}$ calcium ionophore A23178 (61.9\% vs. 32.4\%, respectively) (Moawad, 2005; Moawad et al., 2012a). Furthermore, treatment of epididymal camel spermatozoa with heparin $(10 \mu \mathrm{g} / \mathrm{mL})$ or theophylline $(1 \mathrm{mg} / \mathrm{mL})$ before IVF resulted in $38.5 \%$ and $54.1 \%$, fertilization rates, respectively (Moawad, 2005; Moawad et al., 2012a). Among the different capacitating agents used in our studies, we noticed that caffeine treated spermatozoa produced the highest frequencies of oocytes with 2 pronuclei (Moawad, 2005; Moawad et al., 2012a). We also demonstrated that storage of camel epididymides for $24 \mathrm{~h}$ at $4^{\circ} \mathrm{C}$ did not negatively impact IVF rates (Moawad, 2005; Moawad et al., 2012a). Taken together, under our experimental conditions, epididymal spermatozoa at a concentration of 2 $\times 10^{6}$ sperm/mL prepared in medium containing $5 \mathrm{mM}$ caffeine as capacitating agent can be used effectively for IVF of camel oocytes (Moawad et al., 2012a).

\section{IN VITRO CULTURE OF DROMEDARY CAMEL EMBRYOS}

Experiments on sperm capacitation and fertilization must be followed by appropriate IVC procedures to enable zygotes to develop up to the blastocyst stage (Jaakma et al., 1997). Methods to maintain embryo viability and development in vitro are essential for the success of many experimental protocols, including embryo transfer, SCNT, and other embryo micromanipulations (Wright and Bondioli, 1981). Three systems have been developed to culture the presumptive zygotes (Galli and Lazzari, 1996); namely, 1) zygotes or cleaved embryos are transferred to ligated oviducts of temporary recipients either sheep or rabbit for 5 or 4 days, respectively, 2) zygotes are co-cultured in vitro with somatic cells either oviductal epithelial cells or granulosa cells, and 3) zygotes are cultured in simple media without any somatic cell support. In dromedary camel, in most of IVF studies, the reported cleavage rates ranged from $10 \%$ to $65 \%$ and blastocyst production rates from 0\% to 34\% (Moawad, 2005; Khatir et al., 2005, 2009; Khatir and Anouassi, 2006; Wani, 2009; Moawad et al., 2012a; Fathi et al., 2014; Fathi and El-Shahat, 2017; Fathi et al., 2018). The differences observed between these studies might be attributed to different factors such as the source of semen (epididymal vs. fresh), media used to culture zygotes, and the developmental competence of oocytes (Moawad, 2005; Wani, 2009; Moawad et al., 2012a; Fathi et al., 2014; Fathi and El-Shahat, 2017). Various media have been developed for culturing dromedary camel zygotes include TCM-199 supplemented with FCS (Khatir et al., 2004; Moawad, 2005; Moawad et al., 2012a), TCM199 enhanced with EDS (Wani, 2009), and potassium simplex optimized medium (KSOM) (Khatir and Anouassi, 2006; Fathi et al., 2014; Fathi and El-Shahat, 2017; Fathi et al., 2018). Previous studies showed that culture of in vitro produced dromedary camel zygotes in TCM-199 media with oviductal cell co-culture system resulted in higher cleavage and blastocyst rates (61\% and 10\%, respectively) than those cultured in the same medium supplemented with granulosa cell co-culture ( $45 \%$ and $0 \%$, respectively) (Khatir et al., 2004). The beneficial effect of the oviductal cell co-culture system has been explained based on the ability of these cells to produce some favorable factors that support embryo development (Khatir et al., 2004). Low rates of development obtained with the granulosa cells co-culture system may be due to the high concentration (relative to oviduct co-culture) of cells in the monolayer; many cells may result in greater competition for nutrients or their metabolic waste which may impair 


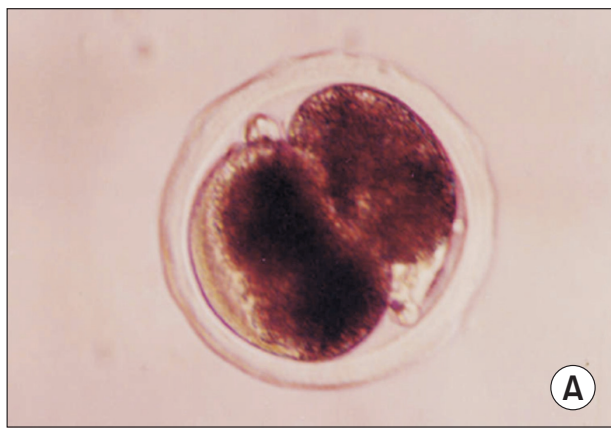

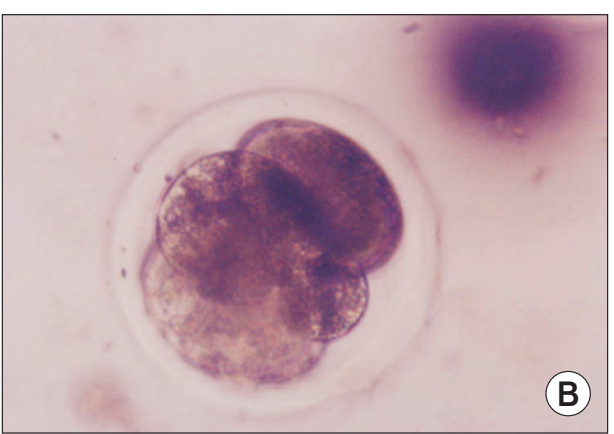

Fig. 8. Dromedary camel day 2 cleaved embryos produced by IVF of IVM camel oocytes with epididymal spermatozoa. (A) 2 cell-embryos, (B) 4 cell-embryos modified from (Moawad, 2005). embryo development (Khatir et al., 2004). In our studies, we observed that insemination of dromedary camel oocytes with epididymal spermatozoa treated with $5 \mathrm{mM}$ caffeine resulted in higher cleavage rates (26.8\%) than those inseminated with spermatozoa treated with $1 \mathrm{mg} /$ $\mathrm{mL}$ theophylline (10.5\%, Fig. 8) (Moawad, 2005; Moawad et al., 2012a). However, we did not see significant differences in morula ( $12.5 \%$ vs. $5.3 \%$, respectively) and blastocyst ( $5.4 \%$ vs. $2.6 \%$, respectively) development between the two groups (Moawad, 2005; Moawad et al., 2012a). In the dromedary camel IVF system, it is worth to highlight that, first cleavages are observed at $16-18 \mathrm{~h}$ post-IVF, and first blastocysts appear at day 5 post-IVF (Khatir et al., 2004; Moawad, 2005; Wani, 2009; Moawad et al., 2012a). This indicates that embryo kinetics in dromedary camel is faster than those reported in cattle, where a blastocyst appears at day 7 post-IVF (Bavister, 1995). This rapid development of a dromedary embryo is also confirmed in vivo. In camel embryo transfer programs, most of the embryos collected at day 7 from induction of ovulation are expanded and hatched blastocysts (Skidmore et al., 2002; Skidmore and Billah, 2011).

\section{CONCLUSION}

Selection and genetic manipulation cause loss of biodiversity, leading to a decrease in disease resistance, reproductive ability, and adaptability to the changing environment. The application of ARTs gives rise to many ethical considerations relating to animal health, welfare, and integrity on one hand and human, biological and environmental issues on the other. ARTs such as artificial insemination, superovulation, embryo transfer, and IVF have been introduced to overcome the reproductive inefficiencies, thus contributing to increased genetic gain. Successful IVF technology in the dromedary camel has the potential to overcome several problems, including infertility due to oviductal abnormities and the low yield of embryos collected after superovulation. Besides, IVF technology in the dromedary will improve our understanding of the fundamental mechanisms of fertilization and early embryo development and promote the development of other techniques, including cryopreservation of oocytes and embryos, embryo sexing, somatic cell cloning and transgenesis. Here we discussed various factors that are known to impact the success of every step in IVP in dromedary camels. We also highlighted our investigations that we reported on the IVM and IVF of dromedary camel oocytes.

\section{CONFLICTS OF INTEREST}

No potential conflict of interest relevant to this article was reported.

\section{AUTHOR CONTRIBUTIONS}

A.R.M. conceived the research idea and experimental designs, executed the experiments, analyzed the data, wrote-edited the original draft, and reviewed the manuscript. I.M.G. contributed to the research idea and experimental designs, edited and reviewed the manuscript. G.M.D. contributed to the research idea and experimental designs, helped in the experiments, and reviewed the manuscript. M.R.B. contributed to the experimental designs, helped in the experiments, and reviewed the manuscript. D.A.E. contributed to the experimental designs, helped in the experiments, and reviewed the manuscript. A.B.A.E. conceived the main research idea and experimental designs, analyzed the data, wrote-edited the original draft, reviewed the manuscript and supervised the project. 


\section{AUTHOR'S POSITION AND ORCID NO.}

\author{
AR Moawad, Associate Professor, \\ https://orcid.org/0000-0003-4397-9688 \\ IM Ghoneim, Professor, \\ https://orcid.org/0000-0002-5600-740X \\ GM Darwish, Professor \\ MR Badr, Professor \\ DA El-Badry, Professor \\ ABA EL-Wishy, Professor, \\ https://orcid.org/0000-0002-0385-1287
}

\section{REFERENCES}

Abd El-Aziz AH, Mahrous UE, Kamel SZ, Sabek AA. 2016. Factors influencing in vitro production of bovine embryos: a review. Asian J. Anim. Vet. Adv. 11:737-756.

Abdel-Khalek EA, El-Harairy MA, Shamiah ShM, Khalil WA. 2010. Effect of ovary preservation period on recovery rate and categories of dromedary camel oocytes. Saudi J. Biol. Sci. 17:231-235.

Abdel-Rahim SEA and El-Nazier AT. 1993. Factors affecting camel reproductive performance in the tropics. In: SaintMartin, G (Ed.), Proceedings of the Workshop - "Is It Possible to Improve the Reproductive Performance of the Camel?", Paris 10-12 September 1990. Institut d'Elevage et de Medecine Veterinaire des Pays Tropicaux Etudes et Syntheses., 41, CIRAD, Dep. d'Élevage et de Méd. Vétérinaire, Maisons-Alfort, pp. 131-148.

Abdelkhalek AE, Gabr SA, Khalil WA, Shamiah SM, Pan L, Qin G, Farouk MH. 2017. In vitro production of Sudanese camel (Camelus dromedarius) embryos from epididymal spermatozoa and follicular oocytes of slaughtered animals. Pol. J. Vet. Sci. 20:95-101.

Abdelrazik H, Sharma R, Mahfouz R, Agarwal A. 2009. L-carnitine decreases DNA damage and improves the in vitro blastocyst development rate in mouse embryos. Fertil. Steril. 91:589-596.

Abdoon AS. 2001. Factors affecting follicular population, oocyte yield and quality in camels (Camelus dromedarius) ovary with special reference to maturation time in vitro. Anim. Reprod. Sci. 66:71-79.

Abdoon AS, Kandil OM, Berisha B, Kliem H, Schams D. 2007. Morphology of dromedary camel oocytes and their ability to spontaneous and chemical parthenogenetic activation. Reprod. Domest. Anim. 42:88-93.

Abdoon AS, Kandil OM, Otoi T, Suzuki T. 2001. Influence of oocyte quality, culture media and gonadotropins on cleavage rate and development of in vitro fertilized buffalo embryos. Anim. Reprod. Sci. 65:215-223.

Akaki Y, Yoshioka K, Noguchi M, Hoshi H, Funahashi H. 2009. Successful piglet production in a chemically defined system for in-vitro production of porcine embryos: dibutyryl cyclic amp and epidermal growth factor-family peptides support in-vitro maturation of oocytes in the absence of gonadotropins. J. Reprod. Dev. 55:446-453.

Aoyagi Y, Fujii K, Iwazumi Y, Furudate M, Fukui Y, Ono H. 1988. Effects of two treatments on semen from different bulls on in vitro fertilization results of bovine oocytes. Theriogenology 30:973-985.

Arthur GH, al-Rahim AT, al-Hindi AS. 1985. Reproduction and genital diseases of the camel. Br. Vet. J. 141:650-659.

Atikuzzaman M, Koo OJ, Kang JT, Kwon DK, Park SJ, Kim SJ, Gomez MN, Oh HJ, Hong SG, Jang G, Lee BC. 2011. The 9-cis retinoic acid signaling pathway and its regulation of prostaglandin-endoperoxide synthase 2 during in vitro maturation of pig cumulus cell-oocyte complexes and effects on parthenogenetic embryo production. Biol. Reprod. 84:1272-1281.

Austin CR. 1951. Observations on the penetration of the sperm in the mammalian egg. Aust. J. Sci. Res. B 4:581-596.

Ball GD, Leibfried ML, Ax RL, First NL. 1984. Maturation and fertilization of bovine oocytes in vitro. J. Dairy Sci. 67:27752785.

Ball GD, Leibfried ML, Lenz RW, Ax RL, Bavister BD, First NL. 1983. Factors affecting successful in vitro fertilization of bovine follicular oocytes. Biol. Reprod. 28:717-725.

Bavister BD. 1995. Culture of preimplantation embryos: facts and artifacts. Hum. Reprod. Update 1:91-148.

Bavister BD, Rose-Hellekant TA, Pinyopummintr T. 1992. Development of in vitro matured/in vitro fertilized bovine embryos into morulae and blastocysts in defined culture media. Theriogenology 37:127-146.

Bedford JM and Kim HH. 1993. Cumulus oophorus as a sperm sequestering device, in vivo. J. Exp. Zool. 265:321-328.

Ben-Ami I, Komsky A, Bern O, Kasterstein E, Komarovsky D, Ron-El R. 2011. In vitro maturation of human germinal vesicle-stage oocytes: role of epidermal growth factor-like growth factors in the culture medium. Hum. Reprod. 26:7681.

Berland MA, von Baer A, Ruiz J, Parraguez VH, Morales $\mathrm{P}$, Adams GP, Ratto MH. 2011. In vitro fertilization and development of cumulus oocytes complexes collected by ultrasound-guided follicle aspiration in superstimulated llamas. Theriogenology 75:1482-1488.

Bevers MM, Dieleman SJ, van den Hurk R, Izadyar F. 1997. Regulation and modulation of oocyte maturation in the bovine. Theriogenology 47:13-22.

Bou SG, Pang YF, Zhang SL, Xue XX. 1993. Preliminary study on in vitro fertilization in the domestic camel (Camelus bactrianus). Chin. J. Zool. 28:35-37.

Brackett BG, Bousquet D, Boice ML, Donawick WJ, Evans JF, Dressel MA. 1982. Normal development following in vitro fertilization in the cow. Biol. Reprod. 27:147-158.

Brackett BG and Oliphant G. 1975. Capacitation of rabbit spermatozoa in vitro. Biol. Reprod. 12:260-274.

Brackett BG and Zuelke KA. 1993. Analysis of factors involved in the in vitro production of bovine embryos. Theriogenol- 
ogy 39:43-64.

Brogliatti GM, Palasz AT, Rodriguez-Martinez H, Mapletoft RJ, Adams GP. 2000. Transvaginal collection and ultrastructure of llama (Lama glama) oocytes. Theriogenology 54:12691279.

Chang MC. 1951. Fertilizing capacity of spermatozoa deposited into the fallopian tubes. Nature 168:697-698.

Chang MC. 1959. Fertilization of rabbit ova in vitro. Nature 184(Suppl 7):466-467.

Chen BX and Yuen ZX. 1979. Reproductive pattern of the Bactrian camel. In: Cockrill WR (Ed.), The Camelid: An All-Purpose Animal, 1. Scandinavian Institute of African Studies, Uppsala, pp. 364-386.

Chen J and Downs SM. 2008. AMP-activated protein kinase is involved in hormone-induced mouse oocyte meiotic maturation in vitro. Dev. Biol. 313:47-57.

Cheng WTK, Moor RM, Polge CE. 1986. In vitro fertilization of pig and sheep oocytes matured in vivo and in vitro. Theriogenology 25:146.

Choi I and Campbell KH. 2010. Treatment of ovine oocytes with caffeine increases the accessibility of DNase I to the donor chromatin and reduces apoptosis in somatic cell nuclear transfer embryos. Reprod. Fertil. Dev. 22:1000-1014.

Crichton EG, Pukazhenthi BS, Billah M, Skidmore JA. 2015. Cholesterol addition aids the cryopreservation of dromedary camel (Camelus dromedarius) spermatozoa. Theriogenology 83:168-174.

Daen FP, Sato E, Naito K, Toyoda Y. 1994. The effect of pig follicular fluid fractions on cumulus expansion and male pronucleus formation in porcine oocytes matured and fertilized in vitro. J. Reprod. Fertil. 101:667-673.

Dale B. 1987. Mechanism of fertilization. Nature 325:762-763.

Das K, Phipps WR, Hensleigh HC, Tagatz GE. 1992. Epidermal growth factor in human follicular fluid stimulates mouse oocyte maturation in vitro. Fertil. Steril. 57:895-901.

Datta TK and Goswami SL. 1999. Effect of quality of buffalo oocytes on their maturation rate in vitro. Indian. J. Anim. Sci. 69:23-26.

de Loos F, Kastrop P, Van Maurik P, Van Beneden TH, Kruip TA. 1991. Heterologous cell contacts and metabolic coupling in bovine cumulus oocyte complexes. Mol. Reprod. Dev. 28:255-259.

Dekel N and Sherizly I. 1985. Epidermal growth factor induces maturation of rat follicle-enclosed oocytes. Endocrinology 116:406-409.

Del Campo MR, Del Campo CH, Adams GP, Mapletoft RJ. 1995. The application of new reproductive technologies to South American camelids. Theriogenology 43:21-30.

Del Campo MR, Del Campo CH, Donoso MX, Berland M. 1994a. In vitro fertilization of llama (Lama glama) follicular oocytes. Theriogenology 41:187.

Del Campo MR, Del Campo CH, Donoso MX, Berland M, Mapletoft RJ. 1994b. In vitro fertilization and development of llama (Lama glama) oocytes using epididymal spermatozoa and oviductal cell co-culture. Theriogenology 41:1219-1229.
Del Campo MR, Donoso MX, Del Camop CH, Rojo RB, C., Parrish JJ, Mapletoft RJ. 1992. In vitro maturation of llama (Lama glama) oocytes. 12th International Congress on Animal Reproduction The Hague, The Netherlands-August 23-27:324326.

Downs SM. 1989. Specificity of epidermal growth factor action on maturation of the murine oocyte and cumulus oophorus in vitro. Biol. Reprod. 41:371-379.

Downs SM, Daniel SA, Eppig JJ. 1988. Induction of maturation in cumulus cell-enclosed mouse oocytes by follicle-stimulating hormone and epidermal growth factor: evidence for a positive stimulus of somatic cell origin. J. Exp. Zool. 245:8696.

Downs SM, Schroeder AC, Eppig JJ. 1986. Serum maintains the fertilizability of mouse oocytes matured in vitro by preventing hardening of the zona pellucida. Gamete Res. 15:115122.

Dunning KR, Cashman K, Russell DL, Thompson JG, Norman RJ, Robker RL. 2010. Beta-oxidation is essential for mouse oocyte developmental competence and early embryo development. Biol. Reprod. 83:909-918.

Dunning KR and Robker RL. 2012. Promoting lipid utilization with 1-carnitine to improve oocyte quality. Anim. Reprod. Sci. 134:69-75.

Eckert J and Niemann H. 1995. In vitro maturation, fertilization and culture to blastocysts of bovine oocytes in protein-free media. Theriogenology 43:1211-1125.

Edwards RG. 1965. Maturation in vitro of mouse, sheep, cow, pig, rhesus monkey and human ovarian oocytes. Nature 208:349-351.

El-Wishy AB. 1987. Reproduction in the female dromedary (Camelus dromedarius): a review. Anim. Reprod. Sci. 15: 273-297.

El-Wishy AB and Ghoneim IM. 1986. Breeding activity of the camel (Camelus dromedarius). Anim. Reprod. Sci. 11:75-77.

El-Wishy AB and Hemeida NA. 1984. Observations on the ovaries of slaughtered camels (Camelus dromedarius). Vet. Med. J. 32:295-312.

El-Wishy AB, Hemeida NA, Omar MA, Mobarak AM, El Sayed MA. 1981. Functional changes in the pregnant camel with special reference to foetal growth. Br. Vet. J. 137:527-537.

Eppig JJ. 1979a. FSH stimulates hyaluronic acid synthesis by oocyte-cumulus cell complexes from mouse preovulatory follicles. Nature 281:483-484.

Eppig JJ. 1979b. Gonadotropin stimulation of the expansion of cumulus oophori isolated from mice: general conditions for expansion in vitro. J. Exp. Zool. 208:111-120.

Fathi M and El-Shahat KH. 2017. L-carnitine enhances oocyte maturation and improves in vitro development of embryos in dromedary camels (Camelus dromedaries). Theriogenology 104:18-22.

Fathi M, Moawad AR, Badr MR. 2018. Production of blastocysts following in vitro maturation and fertilization of dromedary camel oocytes vitrified at the germinal vesicle stage. PLoS One 13:e0194602. 
Fathi M, Seida AA, Sobhy RR, Darwish GM, Badr MR, Moawad AR. 2014. Caffeine supplementation during IVM improves frequencies of nuclear maturation and preimplantation development of dromedary camel oocytes following IVF. Theriogenology 81:1286-1292.

Fukui Y and Ono H. 1989. Effects of sera, hormones and granulosa cells added to culture medium for in-vitro maturation, fertilization, cleavage and development of bovine oocytes. J. Reprod. Fertil. 86:501-506.

Fukushima M and Fukui Y. 1985. Effects of gonadotropins and steroids on the subsequent fertilizability of extrafollicular bovine oocytes cultured in vitro. Anim. Reprod. Sci. 9:323332 .

Gadella BM, Rathi R, Brouwers JF, Stout TA, Colenbrander B. 2001. Capacitation and the acrosome reaction in equine sperm. Anim. Reprod. Sci. 68:249-265.

Galli C and Lazzari G. 1996. Practical aspects of IVM/IVF in cattle. Anim. Reprod. Sci. 42:371-379.

Garbers DL, First NL, Sullivan JJ, Lardy HA. 1971. Stimulation and maintenance of ejaculated bovine spermatozoan respiration and motility by caffeine. Biol. Reprod. 5:336-339.

Ghoneim IM. 1999. In vitro maturation of cumulus oocyte complexes of pregnant and non-pregnant Camelus dromedarius. J. Egypt. Vet. Med. Ass. 59:1649-1659.

Glogowski J, Danforth DR, Ciereszko A. 2002. Inhibition of alkaline phosphatase activity of boar semen by pentoxifylline, caffeine, and theophylline. J. Androl. 23:783-792.

Goto K, Kajihara Y, Koba M, Kosaka S, Nakanishi Y, Ogawa K. 1989. In vitro fertilization and development of in vitro matured bovine follicular oocytes. J. Anim. Sci. 67:2181-2185.

Goud PT, Goud AP, Qian C, Laverge H, Van der Elst J, De Sutter P, Dhont M. 1998. In-vitro maturation of human germinal vesicle stage oocytes: role of cumulus cells and epidermal growth factor in the culture medium. Hum. Reprod. 13:16381644.

Grupen CG. 2014. The evolution of porcine embryo in vitro production. Theriogenology 81:24-37.

Guignot F, Bezard J, Palmer E. 1999. Effect of time during transport of excised mare ovaries on oocyte recovery rate and quality after in vitro maturation. Theriogenology 52:757-766.

Hanada A. 1985. In vitro fetilization in goats. Jpn. J. Anim. Reprod. 31:21-26.

Hemeida NA, Abd-Elfatah A, Elsayed MA, Kandil OM. 2015. Effect of culture media and epidermal growth factor on in vitro oocyte maturation in the one-humped camel (Camelus dromedarius). Int. J. Chemtech Res. 8:130-141.

Ikeda S, Kitagawa M, Imai H, Yamada M. 2005. The roles of vitamin A for cytoplasmic maturation of bovine oocytes. J. Reprod. Dev. 51:23-35.

Iritani A, Kasai M, Niwa K, Song HB. 1984. Fertilization in vitro of cattle follicular oocytes with ejaculated spermatozoa capacitated in a chemically defined medium. J. Reprod. Fertil. 70:487-492.

Jaakma U, Zhang BR, Larsson B, Niwa K, Rodriguez-Martinez H. 1997. Effects of sperm treatments on the in vitro develop- ment of bovine oocytes in semidefined and defined media. Theriogenology 48:711-720.

Jain GC, Das GK, Solanki VS, Tripathi VN. 1995. Comparative efficiency of three different collection techniques for oocyte retrieval in buffaloes. Theriogenology 43:240.

Johnston LA, O'Brien SJ, Wildt DE. 1989. In vitro maturation and fertilization of domestic cat follicular oocytes. Gamete Res. 24:343-356.

Kafi M, McGowan MR, Kirkland PD. 2002. In vitro maturation and fertilization of bovine oocytes and in vitro culture of presumptive zygotes in the presence of bovine pestivirus. Anim. Reprod. Sci. 71:169-179.

Kafi M, Mesbah F, Nili H, Khalili A. 2005. Chronological and ultrastructural changes in camel (Camelus dromedarius) oocytes during in vitro maturation. Theriogenology 63:24582470 .

Kan M and Yamane I. 1983. Oxygen-dependent growth declining and effect of vitamin $\mathrm{E}$ for human diploid fibroblasts in serum-free, BSA-containing culture. Tohoku J. Exp. Med. 139:389-398.

Kawakami E, Arai T, Nakamura U. 1999. Effects of medium containing heparin and theophylline on capacitation and metabolic enzyme activities of ejaculated spermatozoa from dogs with asthenozoospermia. Anim. Reprod. Sci. 54:251-259.

Keefer CL, Stice SL, Maki-Laurila M. 1991. Bovine embryo development in vitro: effect of in vitro maturation conditions on fertilization and blastocyst development. Theriogenology 35:223.

Khatir H and Anouassi A. 2006. The first dromedary (Camelus dromedarius) offspring obtained from in vitro matured, in vitro fertilized and in vitro cultured abattoir-derived oocytes. Theriogenology 65:1727-1736.

Khatir H, Anouassi A, Tibary A. 2004. Production of dromedary (Camelus dromedarius) embryos by IVM and IVF and coculture with oviductal or granulosa cells. Theriogenology 62:1175-1185.

Khatir H, Anouassi A, Tibary A. 2005. In vitro and in vivo developmental competence of dromedary (Camelus dromedarius) embryos produced in vitro using two culture systems (mKSOMaa and oviductal cells). Reprod. Domest. Anim. 40:245-249.

Khatir H, Anouassi A, Tibary A. 2009. In vitro and in vivo developmental competence of dromedary (Camelus dromedarius) oocytes following in vitro fertilization or parthenogenetic activation. Anim. Reprod. Sci. 113:212-219.

Kikuchi K, Naito K, Noguchi J, Shimada A, Kaneko H, Yamashita M, Aoki F, Tojo H, Toyoda Y. 2000. Maturation/M-phase promoting factor: a regulator of aging in porcine oocytes. Biol. Reprod. 63:715-722.

Kitiyanant Y, Chaisalee B, Pavasuthipaisit K. 2002. Evaluation of the acrosome reaction and viability in buffalo spermatozoa using two staining methods: the effects of heparin and calcium ionophore A23187. Int. J. Androl. 25:215-222.

Kito S and Bavister BD. 1997. Gonadotropins, serum, and amino acids alter nuclear maturation, cumulus expansion, and 
oocyte morphology in hamster cumulus-oocyte complexes in vitro. Biol. Reprod. 56:1281-1289.

Kito S, Iritani A, Bavister BD. 1997. Effects of volume, culture media and type of culture dish on in vitro development of hamster 1-cell embryos. Theriogenology 47:541-548.

Köhler-Rollefson I. 1993. About camel breeds: a reevaluation of current classification systems. J. Anim. Breed. Genet. 110:6673.

Konishi M, Aoyagi Y, Takedomi T, Itakura H, Itoh T, Yazawa S. 1996. Presence of granulosa cells during oocyte maturation improved in vitro development of IVM-IVF bovine oocytes that were collected by ultrasound-guided transvaginal aspiration. Theriogenology 45:573-581.

Kumar A, Solanki VS, Jindal SK, Tripathi VN, Jain GC. 1997. Oocyte retrieval and histological studies of follicular population in buffalo ovaries. Anim. Reprod. Sci. 47:189-195.

Lee CN and Ax RL. 1984. Concentrations and composition of glycosaminoglycans in the female bovine reproductive tract. J. Dairy Sci. 67:2006-2009.

Lee JH and Campbell KH. 2006. Effects of enucleation and caffeine on maturation-promoting factor (MPF) and mitogenactivated protein kinase (MAPK) activities in ovine oocytes used as recipient cytoplasts for nuclear transfer. Biol. Reprod. 74:691-698.

Lenz RW, Ball GD, Leibfried ML, Ax RL, First NL. 1983. In vitro maturation and fertilization of bovine oocytes are temperature-dependent processes. Biol. Reprod. 29:173-179.

Liang S, Kang J, Jin H, Liu X, Li J, Li S, Lu Y, Wang W, Yin XJ. 2012. The influence of 9-cis-retinoic acid on nuclear and cytoplasmic maturation and gene expression in canine oocytes during in vitro maturation. Theriogenology 77:11981205.

Livingston T, Rich K, MacKenzie S, Godkin JD. 2009. Glutathione content and antioxidant enzyme expression of in vivo matured sheep oocytes. Anim. Reprod. Sci. 116:265-273.

Lonergan P and Fair T. 2014. The ART of studying early embryo development: progress and challenges in ruminant embryo culture. Theriogenology 81:49-55.

Lonergan P and Fair T. 2016. Maturation of oocytes in vitro. Annu. Rev. Anim. Biosci. 4:255-268.

Lonergan P, Vergos E, Kinis A, Sharif H, Gallagher M, Gordon I. 1991. The effect of recovery method on the type of bovine oocyte obtained for in vitro maturation. Theriogenology 35:231.

Lorenzo PL, Liu IK, Illera JC, Picazo RA, Carneiro GF, Illera MJ, Conley AJ, Enders AC, Illera M. 2001. Influence of epidermal growth factor on mammalian oocyte maturation via tyrosine-kinase pathway. J. Physiol. Biochem. 57:15-22.

Love LB, Choi YH, Love CC, Varner DD, Hinrichs K. 2003. Effect of ovary storage and oocyte transport method on maturation rate of horse oocytes. Theriogenology 59:765-774.

Lu KH, Gordon I, Gallagher M, McGovern H. 1987. Pregnancy established in cattle by transfer of embryos derived from in vitro fertilisation of oocytes matured in vitro. Vet. Rec. 121:259-260.
Maalouf WE, Lee JH, Campbell KH. 2009. Effects of caffeine, cumulus cell removal and aging on polyspermy and embryo development on in vitro matured and fertilized ovine oocytes. Theriogenology 71:1083-1092.

Madan ML, Singla SK, Jailkhani S, Ambrose JD. 1991. In vitro fertilization in buffalo and birth of first ever IVF buffalo calf. In: Alexiev A, Vlahov K (Eds.), Third World Buffalo Congress, Bulgaria, Varna, May 1991: Post-Congress Proceedings Volume. Agricultural Academy, Sofia, pp. 11-17.

Mahmoud KG, El Shahat KH, El Nattat WS. 2003. Chromosome configuration during in vitro maturation of dromedary camel oocytes. Vet. Med. J. 51:411-420.

Mansour G, Abdelrazik H, Sharma RK, Radwan E, Falcone T, Agarwal A. 2009. L-carnitine supplementation reduces oocyte cytoskeleton damage and embryo apoptosis induced by incubation in peritoneal fluid from patients with endometriosis. Fertil. Steril. 91(5 Suppl):2079-2086.

Marie M and Anouassi A. 1986. Mating-induced luteinizing hormone surge and ovulation in the female camel (Camelus dromedarius). Biol. Reprod. 35:792-798.

Marteil G, Richard-Parpaillon L, Kubiak JZ. 2009. Role of oocyte quality in meiotic maturation and embryonic development. Reprod. Biol. 9:203-224.

Martino A, Palomo MJ, Mogas T, Paramio MT. 1994. Influence of the collection technique of prepubertal goat oocytes on in vitro maturation and fertilization. Theriogenology 42:859873.

Moawad AR. 2005. In vitro maturation and fertilization of camel oocytes. Thesis, Cairo University.

Moawad AR, Choi I, Zhu J, Campbell KH. 2011. Ovine oocytes vitrified at germinal vesicle stage as cytoplast recipients for somatic cell nuclear transfer (SCNT). Cell. Reprogram. 13:289-296.

Moawad AR, Choi I, Zhu J, El-Wishy ABA, Amarnath D, Chen W, Campbell KHS. 2018. Caffeine and oocyte vitrification: sheep as an animal model. Int. J. Vet. Sci. Med. 6(Suppl):S41-S48.

Moawad AR, Darwish GM, Badr MR, El-Wishy AB. 2012a. In vitro fertilization of dromedary camel (Camelus dromedarius) oocytes with epididymal spermatozoa. Reprod. Fertil. Dev. 24:192-193.

Moawad AR, Fisher P, Zhu J, Choi I, Polgar Z, Dinnyes A, Campbell KH. 2012b. In vitro fertilization of ovine oocytes vitrified by solid surface vitrification at germinal vesicle stage. Cryobiology 65:139-144.

Moawad AR, Tan SL, Xu B, Chen HY, Taketo T. 2013. L-carnitine supplementation during vitrification of mouse oocytes at the germinal vesicle stage improves preimplantation development following maturation and fertilization in vitro. Biol. Reprod. 88:104.

Moawad AR, Xu B, Tan SL, Taketo T. 2014. 1-carnitine supplementation during vitrification of mouse germinal vesicle stage-oocytes and their subsequent in vitro maturation improves meiotic spindle configuration and mitochondrial distribution in metaphase II oocytes. Hum. Reprod. 29:22562268. 
Moodie G and Graham E. 1989. The effect of incubating sheep ovaries for various times and temperatures on oocyte maturation rates in vitro. Biol. Reprod. 40:53.

Moor RM and Trounson AO. 1977. Hormonal and follicular factors affecting maturation of sheep oocytes in vitro and their subsequent developmental capacity. J. Reprod. Fertil. 49:101-109.

Morriss-Kay GM and Ward SJ. 1999. Retinoids and mammalian development. Int. Rev. Cytol. 188:73-131.

Motlík J, Pavlok A, Lapathitis G, Kubelka M. 2000. Impact of two-step in vitro culture systems on developmental potency of oocytes. Reprod. Domest. Anim. 35:267-271.

Musa BE and Abusineina ME. 1978. The oestrous cycle of the camel (Camelus dromedarius). Vet. Rec. 103:556-557.

Nagai T, Bing Y, Rodriguez-Martinez H. 2000. Effect of cysteamine and FSH on in vitro maturation of porcine oocytes. Theriogenology. 53:461.

Nasiri E, Mahmoudi R, Bahadori MH, Amiri I. 2011. The effect of retinoic acid on in vitro maturation and fertilization rate of mouse germinal vesicle stage oocytes. Cell J. 13:19-24.

Nili H, Mesbah F, Kafi M, Nasr Esfahani MH. 2004. Light and transmission electron microscopy of immature camelus dromedarius oocyte. Anat. Histol. Embryol. 33:196-199.

Niwa K, Ohara K, Hosoi Y, Iritani A. 1985. Early events of invitro fertilization of cat eggs by epididymal spermatozoa. J. Reprod. Fertil. 74:657-660.

Niwa K and Ohgoda O. 1988. Synergistic effect of caffeine and heparin on in-vitro fertilization of cattle oocytes matured in culture. Theriogenology 30:733-741.

Novoa C. 1970. Reproduction in Camelidae. J. Reprod. Fertil. 22:3-20.

Nowshari MA. 2005. The effect of harvesting technique on efficiency of oocyte collection and different maturation media on the nuclear maturation of oocytes in camels (Camelus dromedarius). Theriogenology 63:2471-2481.

O’Brien JK, Rhodes SL, Maxwell WMC, Evans G. 1994. Hormonal requirements for in vitro maturation of sheep oocyte. Theriogenology 41:266.

Palmer E, Bézard J, Magistrini M, Duchamp G. 1991. In vitro fertilization in the horse. A retrospective study. J. Reprod. Fertil. Suppl. 44:375-384.

Pandey A, Gupta SC, Gupta N. 2010. Effect of FSH and LH hormones on oocyte maturation of buffalo and gene expression analysis of their receptors and $\mathrm{Cx} 43$ in maturing oocytes. Zygote 18:231-234.

Paramio MT and Izquierdo D. 2016. Recent advances in in vitro embryo production in small ruminants. Theriogenology 86:152-159.

Parrish JJ. 2014. Bovine in vitro fertilization: in vitro oocyte maturation and sperm capacitation with heparin. Theriogenology 81:67-73.

Parrish JJ, Susko-Parrish JL, Leibfried-Rutledge ML, Critser ES, Eyestone WH, First NL. 1986. Bovine in vitro fertilization with frozen-thawed semen. Theriogenology 25:591-600.

Pawshe CH, Totey SM, Jain SK. 1994. A comparison of three methods of recovery of goat oocytes for in vitro maturation and feritilization. Theriogenology 42:117-125.

Pincus G and Enzmann EV. 1935. The comparative behavior of mammalian eggs in vivo and in vitro: $i$. The activation of ovarian eggs. J. Exp. Med. 62:665-675.

Procházka R, Petlach M, Nagyová E, Nemcová L. 2011. Effect of epidermal growth factor-like peptides on pig cumulus cell expansion, oocyte maturation, and acquisition of developmental competence in vitro: comparison with gonadotropins. Reproduction 141:425-435.

Pu Y, Wang Z, Bian Y, Zhang F, Yang P, Li Y, Zhang Y, Liu Y, Fang F, Cao H, Zhang X. 2014. All-trans retinoic acid improves goat oocyte nuclear maturation and reduces apoptotic cumulus cells during in vitro maturation. Anim. Sci. J. 85:833-839.

Purohit GN, Datt M, Sharma SS. 1999. Efficiency of three methods of oocyte recovery in the dromedary camel (Camelus dromedarius). Indian J. Anim. Sci. 69:88-90.

Rath D and Niemann H. 1997. In vitro fertilization of porcine oocytes with fresh and frozen-thawed ejaculated or frozenthawed epididymal semen obtained from identical boars. Theriogenology 47:785-793.

Ratto M, Gomez C, Berland M, Adams GP. 2007. Effect of ovarian superstimulation on COC collection and maturation in alpacas. Anim. Reprod. Sci. 97:246-256.

Ravindranatha BM, Nandi S, Gupta PSP, Sarma PV. 2001. Comparison of three different media on maturation of buffalo oocytes in vitro. Indian J. Anim. Sci. 71:841-843.

Ravindranatha BM, Nandi S, Raghu HM, Reddy SM. 2003. In vitro maturation and fertilization of buffalo oocytes: effects of storage of ovaries, IVM temperatures, storage of processed sperm and fertilization media. Reprod. Domest. Anim. 38:21-26.

Richani D, Ritter LJ, Thompson JG, Gilchrist RB. 2013. Mode of oocyte maturation affects EGF-like peptide function and oocyte competence. Mol. Hum. Reprod. 19:500-509.

Rieger D, Luciano AM, Modina S, Pocar P, Lauria A, Gandolfi F. 1998. The effects of epidermal growth factor and insulin-like growth factor I on the metabolic activity, nuclear maturation and subsequent development of cattle oocytes in vitro. J. Reprod. Fertil. 112:123-130.

Rose TA and Bavister BD. 1992. Effect of oocyte maturation medium on in vitro development of in vitro fertilized bovine embryos. Mol. Reprod. Dev. 31:72-77.

Saadeldin IM, Swelum AA, Elsafadi M, Mahmood A, Yaqoob SH, Alfayez M, Alowaimer AN. 2019. Effects of all-trans retinoic acid on the in vitro maturation of camel (Camelus dromedarius) cumulus-oocyte complexes. J. Reprod. Dev. 65:215-221.

Samper JC, Behnke EJ, Byers AP, Hunter AG, Crabo BG. 1989. In vitro capacitation of stallion spermatozoa in calciumfree Tyrode's medium and penetration of zona-free hamster eggs. Theriogenology 31:875-884.

Sansinena MJ, Taylor SA, Taylor PJ, Denniston RS, Godke RA. 2003. Production of nuclear transfer llama (lama glama) embryos from in vitro matured llama oocytes. Cloning Stem 
Cells 5:191-198.

Sansinena MJ, Taylor SA, Taylor PJ, Schmidt EE, Denniston RS, Godke RA. 2007. In vitro production of llama (Lama glama) embryos by intracytoplasmic sperm injection: effect of chemical activation treatments and culture conditions. Anim. Reprod. Sci. 99:342-353.

Schernthaner W, Schmoll F, Brem G, Schellander K. 1997. Storing bovine ovaries for 24 hours between 15 and $21^{\circ} \mathrm{C}$ does not influence in vitro production of blastocysts. Theriogenology 47:297.

Scholkamy TH, El-Badry DA, Mahmoud KG. 2016. Developmental competence of Dromedary camel oocytes fertilized in vitro by frozen-thawed ejaculated and epididymal spermatozoa. Iran. J. Vet. Res. 17:253-258.

Schroeder AC, Schultz RM, Kopf GS, Taylor FR, Becker RB, Eppig JJ. 1990. Fetuin inhibits zona pellucida hardening and conversion of ZP2 to ZP2f during spontaneous mouse oocyte maturation in vitro in the absence of serum. Biol. Reprod. 43:891-897.

Sghiri A and Driancourt MA. 1999. Seasonal effects on fertility and ovarian follicular growth and maturation in camels (Camelus dromedarius). Anim. Reprod. Sci. 55:223-237.

Shalash MR. 1965. Some reproductive aspects in the female camel. World Rev. Anim. Prod. 1:103-108.

Shimada M, Hernandez-Gonzalez I, Gonzalez-Robayna I, Richards JS. 2006. Paracrine and autocrine regulation of epidermal growth factor-like factors in cumulus oocyte complexes and granulosa cells: key roles for prostaglandin synthase 2 and progesterone receptor. Mol. Endocrinol. 20:1352-1365.

Shioya Y, Kuwayama M, Ueda S, Saitou S, Oota H, Hanada A. 1988. Effect of the time between slaughter and aspiration of follicles on the developmental capability of bovine oocytes matured and fertilized in vitro. Jpn. J. Anim. Reprod. 34:3944.

Skidmore JA. 2011. Reproductive physiology in female Old World Camelids. Anim. Reprod. Sci. 124:148-154.

Skidmore JA and Billah M. 2011. Embryo transfer in the dromedary camel (Camelus dromedarius) using non-ovulated and ovulated, asynchronous progesterone-treated recipients. Reprod. Fertil. Dev. 23:438-443.

Skidmore JA, Billah M, Allen WR. 1995. The ovarian follicular wave pattern in the mated and non-mated dromedary camel (Camelus dromedarius). J. Reprod. Fertil. Suppl. 49:545-548.

Skidmore JA, Billah M, Allen WR. 2002. Investigation of factors affecting pregnancy rate after embryo transfer in the dromedary camel. Reprod. Fertil. Dev. 14:109-116.

Smythe C and Newport JW. Coupling of mitosis to the completion of S phase in Xenopus occurs via modulation of the tyrosine kinase that phosphorylates p34 ${ }^{\mathrm{cdc} 2}$. Cell 1992;68:787797.

Solano R, de Armas R, Pupo CA, Castro FO. 1994. Short term preservation of intrafollicular oocytes at $4^{\circ} \mathrm{C}$. Theriogenology 41:299.

Somfai T, Kaneda M, Akagi S, Watanabe S, Haraguchi S, Mizutani E, Dang-Nguyen TQ, Geshi M, Kikuchi K, Nagai T. 2011.
Enhancement of lipid metabolism with L-carnitine during in vitro maturation improves nuclear maturation and cleavage ability of follicular porcine oocytes. Reprod. Fertil. Dev. 23:912-920.

Sreenan J. 1970. In vitro maturation and attempted fertilization of cattle follicular oocytes. J. Agric. Sci. 75:393-396.

Steinmann KE, Belinsky GS, Lee D, Schlegel R. 1991. Chemically induced premature mitosis: differential response in rodent and human cells and the relationship to cyclin B synthesis and $\mathrm{p} 34^{\mathrm{cdc} 2} /$ cyclin B complex formation. Proc. Natl. Acad. Sci. U. S. A. 88:6843-6847.

Stroud B. 2012. The year 2011 worldwide statistics of embryo transfer in domestic farm animals. IETS Newslet. 50:16-25.

Sutton ML, Cetica PD, Beconi MT, Kind KL, Gilchrist RB, Thompson JG. 2003. Influence of oocyte-secreted factors and culture duration on the metabolic activity of bovine cumulus cell complexes. Reproduction 126:27-34.

Takahashi T, Inaba Y, Somfai T, Kaneda M, Geshi M, Nagai T, Manabe N. 2013. Supplementation of culture medium with L-carnitine improves development and cryotolerance of bovine embryos produced in vitro. Reprod. Fertil. Dev. 25:589599.

Tamilmani G, Rao BS, Vagdevi R, Amarnath D, Naik BR, Mutharao M, Rao VH. 2005. Nuclear maturation of ovine oocytes in cultured preantral follicles. Small Rumin. Res. 60:295-305.

Tellado MN, Alvarez GM, Dalvit GC, Cetica PD. 2014. The conditions of ovary storage affect the quality of porcine oocytes. Adv. Reprod. Sci. 2:57-67.

Thompson JG. 2000. In vitro culture and embryo metabolism of cattle and sheep embryos - a decade of achievement. Anim. Reprod. Sci. 60-61:263-275.

Tibary A and Anouassi A. 1997. Theriogenology in camelidae: anatomy, physiology, pathology and artificial breeding. Actes Editions, Rabat.

Tibary A, Anouassi A, Khatir H. 2005. Update on reproductive biotechnologies in small ruminants and camelids. Theriogenology 64:618-638.

Tibary A, Anouassi A, Sghiri A, Khatir H. 2007. Current knowledge and future challenges in camelid reproduction. Soc. Reprod. Fertil. Suppl. 64:297-313.

Tibary A, Pearson LK, Campbell A. 2015. Embryo transfer in camelids. Spermova 5:234-252.

Tinson AH, McKinnon AO, Singh K, Kuhad KS, Sambyal R. 2001. Oocyte collection techniques in the dromedary camel. Emir. J. Agric. Sci. 13:39-45.

Torner H, Heleil B, Alm H, Ghoneim IM, Srsen V, Kanitz W, Tuchscherer A, Fattouh EM. 2003. Changes in cumulusoocyte complexes of pregnant and non-pregnant camels (Camelus dromedarius) during maturation in vitro. Theriogenology 60:977-987.

Totey SM, Pawshe CH, Singh GP. 1993. In vitro maturation and fertilization of buffalo oocytes (Bubalus bubalis): effects of media, hormones and sera. Theriogenology 39:1153-1171.

Totey SM, Singh G, Taneja M, Pawshe CH, Talwar GP. 1992. In vitro maturation, fertilization and development of follicular 
oocytes from buffalo (Bubalus bubalis). J. Reprod. Fertil. 95:597-607.

Trasorras VL, Carretero MI, Neild DM, Chaves MG, Giuliano SM, Miragaya MH. 2017. Production, preservation, and transfer of South American Camelid embryos. Front. Vet. Sci. 4:190.

Trasorras VL, Chaves MG, Miragaya MH, Pinto M, Rutter B, Flores M, Agüero A. 2009. Effect of eCG superstimulation and buserelin on cumulus-oocyte complexes recovery and maturation in llamas (Lama glama). Reprod. Domest. Anim. 44:359-364.

Tsafriri A, Cao X, Ashkenazi H, Motola S, Popliker M, Pomerantz SH. 2005. Resumption of oocyte meiosis in mammals: on models, meiosis activating sterols, steroids and EGF-like factors. Mol. Cell. Endocrinol. 234:37-45.

van den Hurk R and Zhao J. 2005. Formation of mammalian oocytes and their growth, differentiation and maturation within ovarian follicles. Theriogenology 63:1717-1751.

Visconti PE, Stewart-Savage J, Blasco A, Battaglia L, Miranda P, Kopf GS, Tezón JG. 1999. Roles of bicarbonate, cAMP, and protein tyrosine phosphorylation on capacitation and the spontaneous acrosome reaction of hamster sperm. Biol. Reprod. 61:76-84.

Wani NA. 2009. In vitro embryo production in camel (Camelus dromedarius) from in vitro matured oocytes fertilized with epididymal spermatozoa stored at 4 degrees C. Anim. Reprod. Sci. 111:69-79.

Wani NA and Nowshari MA. 2005. Kinetics of nuclear maturation and effect of holding ovaries at room temperature on in vitro maturation of camel (Camelus dromedarius) oocytes. Theriogenology 64:75-85.

Wani NA and Skidmore JA. 2010. Ultrasonographic-guided retrieval of cumulus oocyte complexes after super-stimulation in dromedary camel (Camelus dromedarius). Theriogenology 74:436-442.

Wani $\mathrm{N}$ and Wernery U. 2010. In vitro maturation of dromedary (Camelus dromedarius) oocytes: effect of different protein supplementations and epidermal growth factor. Reprod. Domest. Anim. 45:e189-e193.

Wani NA, Wernery U, Hassan FA, Wernery R, Skidmore JA. 2010. Production of the first cloned camel by somatic cell nuclear transfer. Biol. Reprod. 82:373-379.

Whittingham DG. 1968. Fertilization of mouse eggs in vitro. Nature 220:592-593.

Wilson RT. 1984. The Camel. Longman, Harlow, pp. 83-102.

Wongsrikeao P, Otoi T, Karja NW, Agung B, Nii M, Nagai T. 2005. Effects of ovary storage time and temperature on DNA fragmentation and development of porcine oocytes. J. Reprod. Dev. 51:87-97.

Wright RW Jr and Bondioli KR. 1981. Aspects of in vitro fertil- ization and embryo culture in domestic animals. J. Anim. Sci. 53:702-729.

Xia GL, Kikuchi K, Noguchi J, Izaike Y. 2000. Short time priming of pig cumulus-oocyte complexes with FSH and forskolin in the presence of hypoxanthine stimulates cumulus cells to secrete a meiosis-activating substance. Theriogenology 53:1807-1815.

Xu X, Ding J, Seth PC, Harbison DS, Foxcroft GR. 1996. In vitro fertilization of in vitro matured pig oocytes: effects of boar and ejaculate fraction. Theriogenology 45:745-755.

Yamada T, Imai H, Yamada M. 2006. Beneficial effects of acetylL-carnitine treatment during IVM on post-fertilization development of bovine oocytes in vitro. Reprod. Fertil. Dev. 18:280-281.

Yanagimachi R, Yanagimachi H, Rogers BJ. 1976. The use of zona-free animal ova as a test-system for the assessment of the fertilizing capacity of human spermatozoa. Biol. Reprod. 15:471-476.

Yang NS, Lu KH, Gordon I. 1990. In vitro fertilization (IVF) and culture (IVC) of bovine oocytes from stored ovaries. Theriogenology 33:352.

Yang X, Jiang S, Foote RH. 1993. Bovine oocyte development following different oocyte maturation and sperm capacitation procedures. Mol. Reprod. Dev. 34:94-100.

Yaqoob SH, Saadeldin IM, Swelum AB, Alowaimer AN. 2017. Optimizing camel (Camelus dromedarius) oocytes in vitro maturation and early embryo culture after parthenogenetic activation. Small Rumin. Res. 153:81-86.

Yasin SA and Wahid AA. 1957. Pakistan camels. A preliminary survey. Agric. Pak. 8:289-297.

Yoshida M, Mizoguchi Y, Ishigaki K, Kojima T, Nagai T. 1993. Birth of piglets derived from in vitro fertilization of pig oocytes matured in vitro. Theriogenology 39:1303-1311.

Younis AI, Brackett BG, Fayrer-Hosken RA. 1989. Influence of serum and hormones on bovine oocyte maturation and fertilization in vitro. Gamete Res. 23:189-201.

Yuge M, Otoi T, Nii M, Murakami M, Karja NW, Rajaei F, Agung B, Wongsrikeao P, Murakami M, Suzuki T. 2003. Effects of cooling ovaries before oocyte aspiration on meiotic competence of porcine oocytes and of exposing in vitro matured oocytes to ambient temperature on in vitro fertilization and development of the oocytes. Cryobiology 47:102-108.

Zeidan AEB, El-Harairy MA, Gabr SA, Tag El-Dien MA, Abd ElRahman SA, Amer AM. 2011. In vitro maturation of camel oocytes as affected by different media during breeding and non-breeding seasons. J. Am. Sci. 7:460-472.

Zuelke KA and Brackett BG. 1990. Luteinizing hormoneenhanced in vitro maturation of bovine oocytes with and without protein supplementation. Biol. Reprod. 43:784-787. 